تصميم بيئة تعلم إلكترونيه قائمة

علي استراتيجيتي التعلم النشط

وأثرها في تنمية مهارات تصميم

عناصر التعلم الرقمية لاي طلاب

$$
\text { تكنولوجيا التعليم أسماء ححم الحسيني }
$$

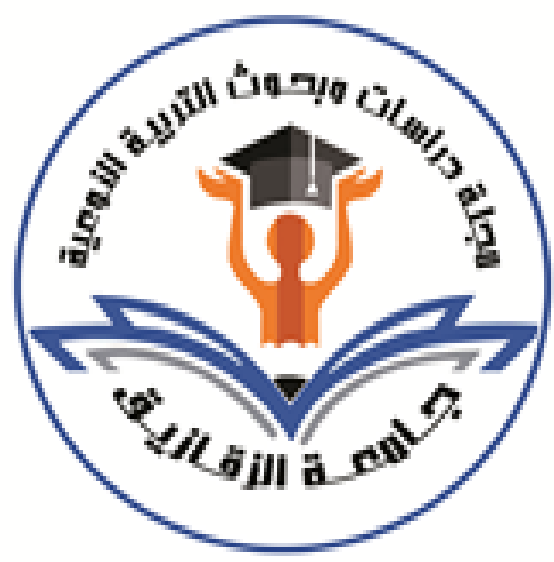

معيدة بقسم تكنولوجيا التعليم كلية التربية

النوعية - جامعة الزقازيق

المجلة العلمية المحمة لاراسات وبحوث التربية النوعية

المجلد السابع- العدد الثاني- مسلسل العدد (14)- يوليو 2021- الجزء الأول

$$
\text { رقم الإيداع بدار الكتب } 24274 \text { لسنة } 2016
$$

ISSN-Print: 2356-8690 ISSN-Online: $2356-8690$

https://jsezu.journals.ekb.eg موقع المجلة عبر بنك المعرفة المصري JSROSE@foe.zu.edu.eg

E-mail البريد الإكتروني للمجلة 


\section{تصميم بيئة تعلم إلكترونيه قائمة علي استراتيجيتي التعلم النشط وأثرها في تنمية مهارات تصميم عناصر التعلم الرقمية لاي طلاب تكنولوجيا التعليم م/ أسماء عحمد الحسيني}

معيدة بقسم تكنولوجيا التعليم كلية التربية النوعية - جامعة الزقازيق

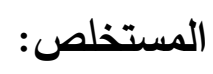

يهذف البحث الحالي إلي تقصي أثر تصميم بيئة تعلم إلكترونية قائمة علي استراتيجية التعلم النشط في تتمية مهارات تصميم عناصر التعلم الرقمية لاي طلاب تكنولوجيا التعليم ، ولتحقيق هذا الهدف تم استخدام المنهج الوصفي التحليلي ، والمنهج شبه التجريبي ، كما تضمنت

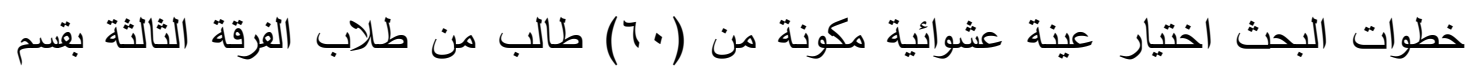
تكنولوجيا التعليم كلية التربية النوعية جامعة الزقازيق. وتمثلت أدوات القياس في( الاختبار التحصيلي وبطاقة الملاحظة) وبعد التطبيق والتعامل مع البيانات الإحصائية أسفرت نتائج البحث عن فاعلية بيئة التعلم الإلكترونية القائمة علي استراتيجية التعلم النشط في تتمية مهارات تصميم عناصر التعلم الرقمية . الكلمات المفتاحية : بيئة التعلم الالكتروني - التعلم النشط - مهارات التصميم - عناصر التعلم

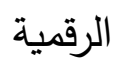

\section{Summary of the research}

The current research aims to investigate the effect of designing an elearning environment based on an active learning strategy in developing the skills of designing digital learning elements for students of educational technology. To achieve this goal, the descriptive analytical approach and the semi-experimental approach were used. 60) A third year student in the Department of Educational Technology, Faculty of Specific Education, Zagazig University.

The measurement tools were (achievement test and observation card), and one of the most important findings of the research was the effectiveness of the e-learning environment based on the active learning strategy in developing the skills of designing digital learning elements.

Keywords: e-learning environment - active learning - design skills digital learning elements. 


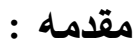

أصبح بناء المحتوي الرقمي من قبل المعلم أمراً مهماً حيث يعتمد بالدرجة الأولي وعلي

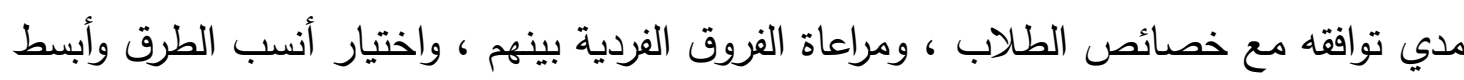
الوسائل التي تساعد علي إيصال المعلومة بأسرع وقت وتكون مناسبة للتطورات التكنولوجية. لذا ظهرت عناصر التعلم الرقمية كمدخل مهم في العملية التعليمية فهي أصغر جزء رقمي من المحتوي وقابل لإعادة الاستخدام في المواقف التعليمية المختلفة، وتتعدد أشكال عناصر التعلم الرقمية ما بين عناصر تعلم نصية، وعناصر تعلم صوتية ، وعناصر تعلم حركية ، وعناصر تعلم مقاطع فيديو، وعناصر تعلم أفلام فيديو وعناصر تعلم تجمع بين أكثر من نوع من

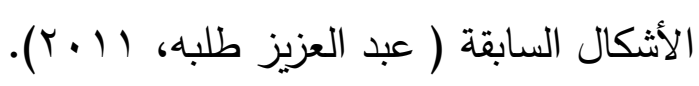

لهذا فإن مهارات تصميم عناصر التعلم الرقمية تعددت ومنها: تحليل محتوي التعلم، وصياغة الأهداف السلوكية ، وتصميم المحتوي التعليمي، تصميم السيناريو التعليمي ، وتصميم

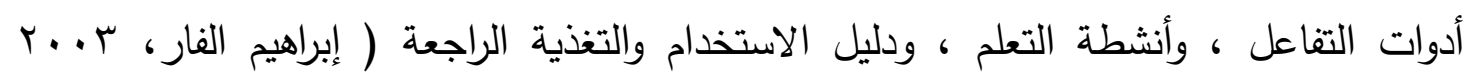
.$(0 \leqslant-0)$ ،

ومن ثم ظهرت عدة استراتيجيات للتعليم الإكتروني كان لها دور كبير في النهوض

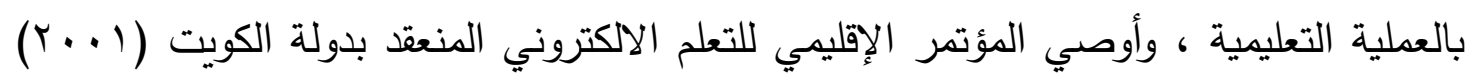
ببناء استراتيجية عربية للتعلم الاككتروني بالتعاون مع المؤسسات التعليمية والجهات ذات العلاقة، وتطوير المناهج الإكترونية والاستفادة منها في المنظومة، لمواكبة التطور في طرق لتهري واستراتيجيات تطبيق التعلم الإلكتروني.

لذا يعد استخدام التعلم التعاوني في العطلية التعليمية من المستحدثات التقنية التربوية حيث

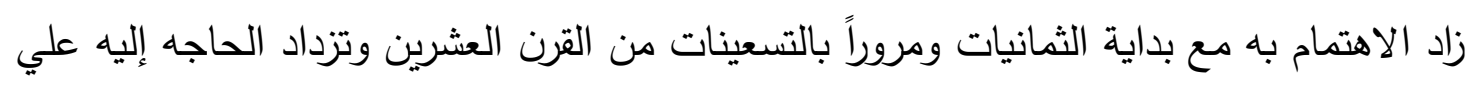
اساس مصداقية اسهامات التعلم التعاوني في تحقيق الأهداف التربوية المرغوب فيها (مجدي

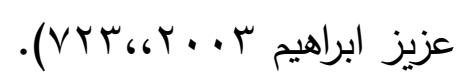
ويمكن تعريف التعلم التعاونى على أنه : استراتيجية يتم من خلالها تقسيم الطلاب فيها إلى لتى مجموعات صغيرة تتكون من (r-0) طلاب ثم يتم تقسيم المادة المراد تعلمها وتوزيعها عليهم ويعين لكل مجموعه قائد ويتم فيه تبادل الادوار فيما بينهم ويتم التقويم فردي وجماعى، وهناك العديد من الدراسات التي هدفت إلي بيان أثر التعلم التعاوني علي التحصيل، كما ورد بدراسة 


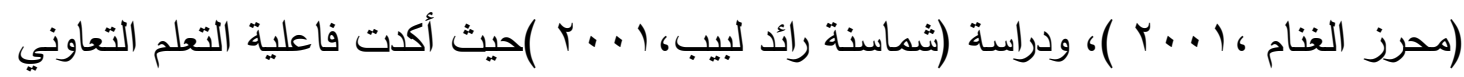
في زيادة التحصيل وأوصت هذة الدراسات بضرورة تطبيق التعلم التعاوني في العملية التعليمية. كما أن هناك بعض الدراسات التي استخدمت التعلم التعاوني ومن هذه الدراسات دراسة

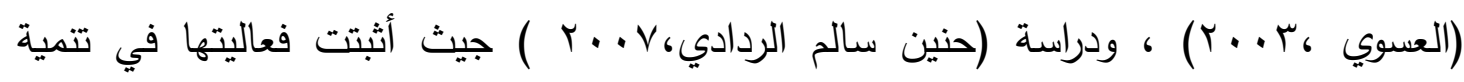
الاتجاهات لدي المواد الدراسية محور الدراسات.

أيضا استراتيجية التعليم الذاتى والتي يستطيع من خلالها المتعلم أن يحقق استراتيجية لكل متعلم تعلماً يتتاسب مع قدراته وسرعتة الذاتية ويعتمد فى ذلك على دافعيته ، كما يأخذ المتعلم فيه دوراً إيجابياً ونشيطاً، إضافة إلى أن التعلم الذاتى يمكُن المتعلم من إتقان المهارات الأساسية اللآزم لمواصلة تعليم نفسه بنغسه ويستمر معه مدى الحياة ، وتدريبة على حل المشكلات لإعداده للمستقبل وتعويدة تحمل المسؤولية بنفسه، وإيجاد بيئه خصبة للإبداع، خاصة وأن العالم يواجه انفجاراً معرفياً متطوراً باستمرارلا تستوعبه نظم التعلم وطرائقها مما يحتم وجود إستراتيجية

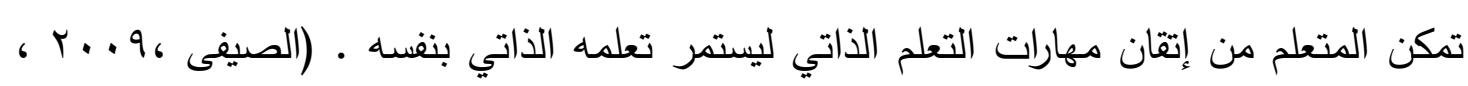
$\cdot\left(r T_{T}, r_{0}\right.$

لذا هناك دراسات اكدت أيضاً علي أهمية التعلم الذاتي في العملية التعليمية ومنها :

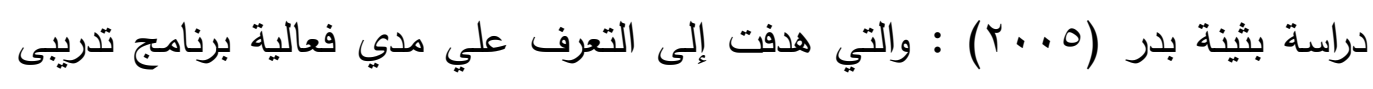
مقترح فى تتمية مهارات التدري لدى الطالبات المعلمات بقسم الرياضيات فى كلية التربية ، وتوصلت الي برنامج تدريبى المقترح لتدريب الطالبات المعلمات على المهارات التدريسية فى ضوء تحديد الاحتياجات التدريبية من خلال التطبيق القبلى لبطاقة الملاحظة . دراسة سامى هزايمة (0 . . r) والتي هدفت إلى التعرف على درجة توافر مهارات تدريس القراءةالناقدة لدى معلمي اللغة العربية للمرحلة الأساسية العليا ، ثملإلي بناء برنامج تدرببي قائم على التعلم الذاتى واختبار أثره فى تتمية مهارات تدريس القراءة الناقدة لدى معلمى اللغة العربية للمرحلة الأساسية العليا فى الأردن وكانت نتائجها إثبات فعالية البرنامج التدريى فى تتمية مهارات تدريس القراءة الناقدة .

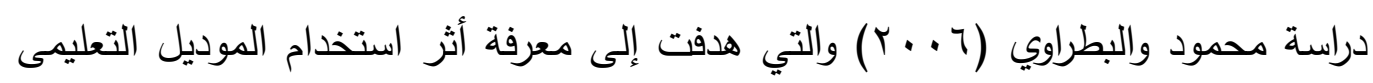
فى تتيمة بعض مهارات التدريس والأتجاه نحو مهنه التدريس والتي توصلت إلي أن الموديولات التعليمية لها أثركبير تتمية بعض مهارات التدري. 
أيضاً دراسة إلهام أبو مشرف (Y. . . P) :التي هدفت إلى بناء برنامج تدريبى قائم على التعلم الذاتى واختبار أثرة فى تتمية مهارات تدريس الكتابة لمعلمات اللغة العربية لمرحلة التعليم

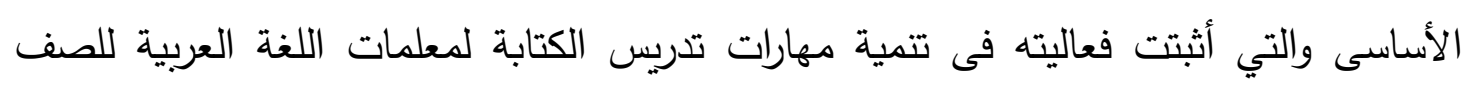
العاشر من مرحلة التعليم الاساسى فى مدارس منطقة شمال عمان التعليمية التابعة لوكالة الغوث

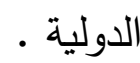

الإحساس بالمشكلة :

نبع الإحساس بمشكلة البحث الحالي من عدة مصادر منها :

أولاً الخبرة العملية للباحثة :

من خلال عمل الباحثة بتدريس المقرر العملي لمادة تطبيقات الحاسب فى التعلم" والتي لاحظت أن الطلاب لا يمتلكون المهارات الكافية لكيفية تصميم عناصر التعلم الرقمية وعدم اتباعهم لخطوات متسلسلة لتصميم عناصر التعلم الرقمية بل يتصف عملهم بالعشوائية ، ونتج عن المعوقات السابقة تدني درجات الطلاب في الاختبار العملي للمادة خلال الثلاث سنوات السابقة .

ثانياً الاراسة الاستكشافية : ولتأكيد المشكلة تم عمل دراسة استكثافية استهدفت تحديد مدي توافر مهارات تصميم عناصر التعلم الرقمية، ومدي الحاجة لتوظيف استراتيجية التعلم التعاوني الرقمية، بطريقة تحقق فاعلية أعلي في تتمية مهارات تصميم عناصر التعلم الرقمية لدي الطلاب وتمت الدراسة الاستكثافية من خلال الأدوات الآتية:

ا. تطبيق استبيان علي عينة من طلاب الفرقة الثالثة قسم تكنولوجيا التعليم شعبة حاسب

$$
\text { آلي وعددهم (ro) }
$$

r. إجراء مقابلات شخصية مع (10 (1) طالب من طلاب تكنولوجيا التعليم .

r. إجراء مقابلات مع القائمين بتدريس الجانب النظري حول إمكانية توظيف استراتيجية

التعلم النشط

وقد أسفرت نتائج الدارسة الاستكثافية عن الآتي :

ا ـ أن ؟\% من مجموع أفراد العينة لا يمتلكون مهارات تصمير عناصر التعلم الرقمية . 
ץ. توجد حاجة ملحة لدراسة مهارات تصميم عناصر التعلم الرقمية في بيئة تعليمية مواكبة للمستحدثات التكنولوجية بحيث تساعد الطلاب علي الممارسة الفعلية وتقديمها بشكل بسيط ومشوق للطلاب. r. يوجد تدني في مستوي الأداء المهاري لمهارات تصميم عناصر التعلم الرقمية . ثالثاً: الاراسات السابقة : كما أظهرت نتائج الاراسات التي اهتمت بعناصر التعلم الرقمية والتي توصلت إلى فاعلية عناصر التعلم الرقمية في العملية التعليمية مثل( "كاي كناك" Kay,Knaack,2008؛ عبدالعزيز

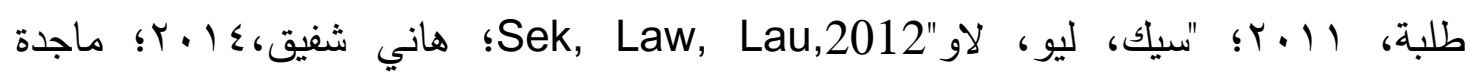

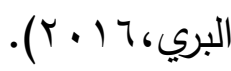
رابعًا: توصيات المؤتمرات : أكدت توصيات المؤتمرات والندوات العلمية في تكنولوجيا التعليم علي بناء جيل جديد يستطيع مواكبة عصر المستحدثات التكنولوجية ومن أهم التوصيات ما يلي : اوصي المؤتمر الدولي الثاني للتعلم الإلكتروني في الوطن العربي (ع ا ـ ب) بأهمية التحول من التعلم التعاوني إلي التعلم الإكتروني باعتبار أن نمط التعلم التعاوني هدفاً تربوياً رئيساً في المناهج والبرامج الدراسية المعاصرة. اوصي مؤتمر تكنولوجيا المعلومات والاتصالات وتطوير الأداء في المؤسسات التعليمية (r ( ا ( ) تعزيز وتشجيع التعلم الإكتروني في المؤسسات التعليمية المختلفة ، تحديث المقررات والمناهج الدراسية وتوظيف التكنولوجيا الحديثة فيها،مع تحديث أساليب التدريس والارتقاء بها لكي تتماشي مع متغير التكنولوجيا الحديثة والتركيز علي الأساليب التدريسية التي تكون قادرة علي استيعاب هذا المتغير بشكل إيجابي وفعال .

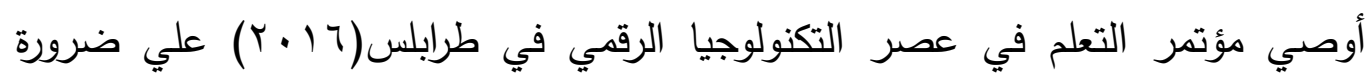
توظيف المستحدثات التقنية الحديثة والمعاصرة في مجال التعليم والتعلم المختلفة والاعتماد علي الوسائط المتعددة لما لها من أهمية في استثارة حواس المتعلمين وتتمية التفكير الإبداعي عندهم وجعل التعليم أكثر عمقاًُ وثباتاًُ في أذهانهم مع تفعيل العمل الجماعي بين الباحثين لتكوين فرق بحث متعددة التخصصات، وتبادل الخبرات. 
مما سبق يمكن تحديد مشكلة البحث في وجود قصور وضعف في مستوي طلاب تكنولوجيا التعليم في مهارات تصميم عناصر التعلم الرقمية لهذا حاول البحث الحالي تحديد مشكلة البحث من خلال الإجابة عن السؤال الرئيس الآتي : ما أثر تصميم بيئة تعلم إلكترونية قائمة علي استراتيجيتي التعلم النشط ( التعلم التعاوني - التعلم الذاتي) في تتمية مهارات تصميم بعض عناصر التعلم لدي طلاب تكنولوجيا التعليم؟

\section{يتفرع من هذا السؤال الآسئلة الفرعية:}

ا. ما مهارات تصميم عناصر التعلم الرقية الواجب توافرها لدي طلاب كلية التربية

$$
\text { النوعية؟ }
$$

r. ما المعايير التصميمية لبيئة التعلم الإلكترونية القائمة علي استراتيجيتي التعلم النشط ؟ r. ما التصميم التعليمي لبيئة تعلم إلكترونية قائمة علي استراتيجيتي التعلم النشط ؟ ء. ما أثر تصميم بيئة تعلم إلكترونية قائمة علي استراتيجيتي التعلم النشط في تتمية لتئه الجوانب؟ المعرفية لمهارات تصميم عناصر التعلم الرقمية لدي طلاب تكنولوجيا التعليم • ه. ما أثر تصميم بيئة تعلم الكتروني قائمة علي استراتيجية التعلم التعاوني في تتمية الجوانب الأدائية لمهارات التصميم عناصر التعلم الرقمية لدي طلاب تكنولوجيا التعليم؟ أهداف البحث :

معرفة أثر تصميم عناصر التعلم الرقية القائمة علي استراتيجيات التعلم النشط . ا. الجوانب المعرفية لتصميم بيئة التعلم الاككتروني القائمة علي استراتيجيتي التعلم النشط. r. الجوانب الأدائية لتصميم عناصر التعلم الرقمية القائمة علي استراتيجيتي التعلم النشط r. تحديد المعايير التصيميمة لبيئة التعلم الالكترونية القائمة علي استراتيجيتي التعلم النشط. أهمية البحث : الأهمية النظرية :

1. مساعدة المتعلمين علي تتمية مهارات تصميم عناصر التعلم الرقمية . 
r. الإرتقاء بالمستوي العلمي والتقني لاي المتعلمين ، والذي ينعكس علي المنظومة

$$
\text { التعليمية ككل . }
$$

r. محاولة تطوير أساليب التدريس المتعلقة بتدريب الطلاب علي التوظيف الأمثل

$$
\text { المشارك في التعلم النشط لدي الطلاب . }
$$

ع. مساعدة أعضاء هيئة التدريس في توظيف المستحدثات التكنولوجيا في التعليم والتجديد

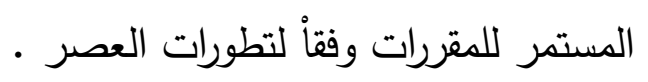

ه. قد تسهم نتائج البحث في تعزيز الإفادة من إمكانيات استخدام استراتيجية كل من:

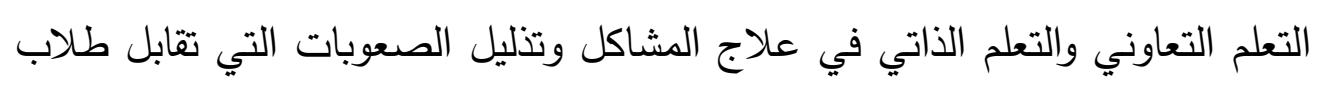

$$
\text { الجامعات عند دراسة بعض المقررات الدراسية . ل }
$$

7. التعرف علي التطبيقات المختلفة لإنتاج عناصر التعلم الرقمية التي تخدم العملية

\section{التعليمية.}

\section{الأهمية التطبيقية :}

ا. تقديم قائمة بمهارات تصميم عناصر التعلم الرقمية الواجب توافرها لاي طلاب كلية

$$
\text { التربية النوعية. }
$$

r. الربط بين الأفكار والمباديء النظريةو المجال العملي التطبيقي ، حيث العلم الذي لتيه يمثل حلقة الوصل بين النظريات والتطبيقات وبدونه لن يكون للنظريات نفع ملموس، كما لن يكون للتطبيقات قيمة تذكر.

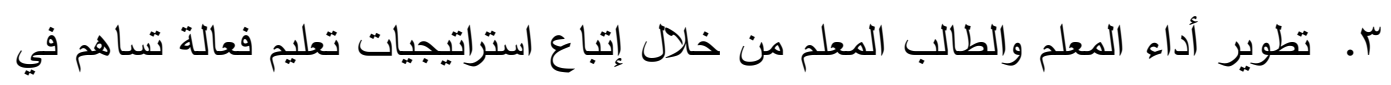

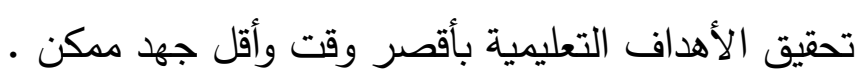
حدود البحث :

\section{تتمثل حدود البحث الحالي فيما يلي :}

1. حدود بشرية :عينة عشوائية من طلال الفرقة الثالثة قسم تكنولوجيا التعليم • r. حدود محتوي : تتضمن مهارات تصميم عناصر التعلم الرقمية المقررة علي الفرقة الثالثة قسم تكنولوجيا تعليم شعبة تكنولوجيا تعليم.

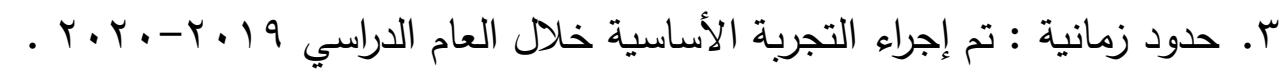
ع. حدود مكانية : معامل كلية التربية النوعية ، جامعة الزقازيق . 


\section{استخدم البحث الحالي : (1الت}

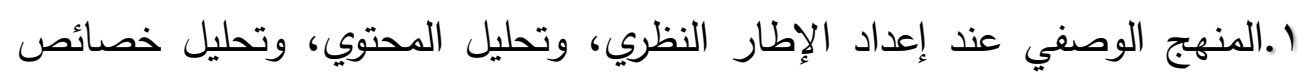
المتعلمين مع فهمها وتحليلها من أجل الوصول لتحديد لمتعلمين وإعدد أدوات البحث وتحليلها من أجل الوصول لتحديد الإحتياجات الفعلية اللازمة لتنمية مهارات تصميم عناصر التعلم الرقمية لدي طلاب تكنولوجيا التعليم • r. المنهج التجريبي القائم علي التصميم شبه التجريبي: في الجانب التطبيقي لدراسة أثر المتغير المستقل علي المتغير التابع. متغيرات البحث :

المتغير المستقل : تصميم بيئة تعلم الكترونية قائمة علي استراتيجيتي التعلم النشط وهما :

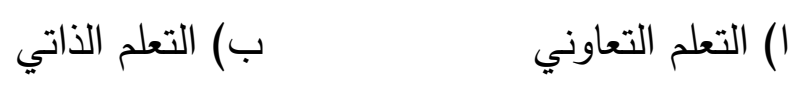

$$
\begin{aligned}
& \text { المتغيرات التابعة : }
\end{aligned}
$$

1- التحصيل المعرفي الخاص بمهارات لتصميم عناصر التعلم الرقمية .

ץ- الأداء المهاري الخاص بمهارات لتصميم عناصر التعلم الرقمية .

أدوات البحث والقياس :

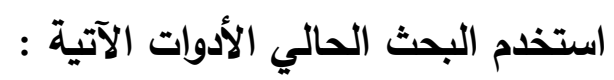

1-اختبار تحصيلي لقياس الجوانب المعرفية المرتبطة بمهارات لتصميم عناصر التعلم الرقمية .

ץ-بطاقة ملاحظة لقياس الجوانب الأدائية المرتبطة بمهارات لتصميم عناصر التعلم الرقمية .

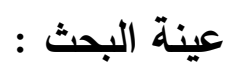

تم اختبار عينة البحث علي مجموعة من طلاب الفرقة الثالثة قسم تكنولوجيا شعبة تكنولوجيا التعليم بكلية التربية النوعية جامعة الزقازيق .

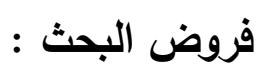

1- يوجد فرق دال إحصائيا عند مستوي ( 0...) بين متوسطي درجات طلاب المجموعة

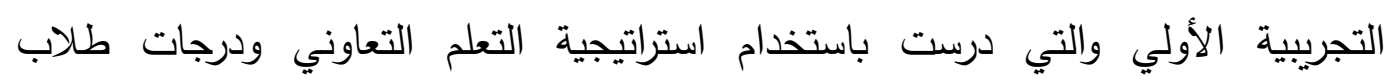


المجموعة التجريبية الثانية والتي درست باستخدام التعلم الذاتي في التحصيل المعرفي لصالح طلاب المجموعة التجريبية الثانية . ץ- يوجد فرق دال إحصائياً عند مستوي( 0.. • بين متوسطي درجات طلاب المجموعة التجريبية الأولي والتي درست استراتيجية التعلم التعاوني ودرجات طلاب المجموعة الثانية والتي درست باستخدام التعلم الذاتي في الأداء المهاري لصالح طلاب المجموعة التجريبية الثانية.

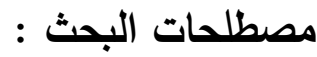

التعريف الإجرائي للتعلم النشط : " يقصد بها إجرائيا بأنه: هو تعلم قائم علي الأنشطة المختلفة التي يمارسها الطلاب، من خلال الموقع التعليمى ودراسة المودولات المختلفة والتي ينتج عنها سلوكيات تعتمد علي مشاركة المتعلم الفعالة والإيجابية فى تعلم مهارات تصميم المواقف التعليميه لدى طلاب تكنولوجيا التعليم الفرقة الرابعة شعبة تكنولوجيا عام ". التعريف الإجرائي للتعلم التعاوني : يقصد بها إجرائيا بأنه: "طريقة يتم فيها تقسيم الطلاب إلى مجموعات صغيرة تتكون من (ب-0) طلاب، ثم يتم تقسيم المادة المراد تعلمها وتوزيعها عليهم ويعين لكل مجموعة قائد، ويتبادلوا الأدوار فيما بينهم، ويتم التقويم فردي وجماعي". التعريف الإجرائي للتعلم الذاتي : يقصد بها إجرائيا بأنه: "عملية مستمرة تتطلبها ظروف الحياة الأساليب التقليدية مناسبته لجميع الطلاب وجميع المستويات والتعلم المعاصرة، يميز ها عن • مسب القدرة الذاتية" - م التعريف الإجرائي لبيئة التعلم الاكتروني : يقصد بها إجرائيا بأنه: "نظام تعلم من خلال موقع إلكترونى قائم على استراتيجتى التعلم النشط · (تعاوني/ذاتي) فى تتمية مهارات تصميم المواقف

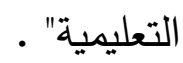
التعريف الإجرائي لعناصر التعلم الرقمية : يقصد بها إجرائيا بأنه: "عناصر تعلم رقمية مثل: الصورة والملصق والفيديو يتم إنتاجها لخدمة الأغراض التعليمية المتعددة باستخدام العديد من البرامج والتطبيقات كتطبيقات جوجل التعليمية. الإطار النظرى للبحث : يستند الإطار النظرى إلى ثلاث محور أساسية وهما كالتالي: المحور الأول استراتيجية التعلم النشط 


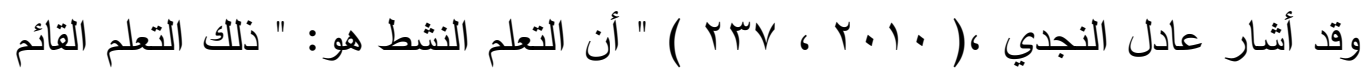
علي الاعتقاد بأنه تعلم الطلاب ينبغي أن يكون نشطاً ، مرتبطاً بخبرة الطلاب وأن يكون شبيهاً

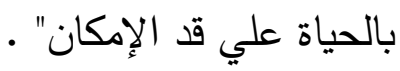

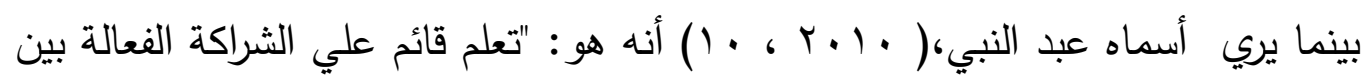
المعلم والمتعلم ، يستخدم المعلم فيه استراتيجيات تدريسية من شأنها أن تساعد المتعلم علي ممارسة المستويات العليا للتفكير من خلال مشاركته الإيجابية في الموقف التعليمي ، تظهر فيه الإصغاء الجيد والقراءة والتأمل العميق والتفسير والملاحظة وتوليد الأفكار" .

أهداف التعلم النشط :

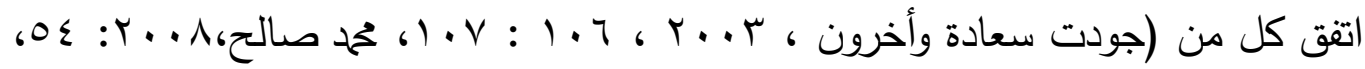

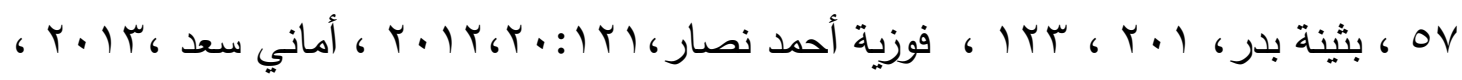

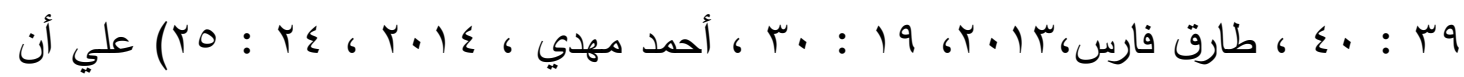
استخدام التعلم النشط في التدريس والتعلم يهذف إلي : 1- تثجيع الطلبة علي اكتساب مهارات التفكير العديدة . r- تشجيع الطلبة علي القراءة الناقدة . r- التتوع في الأنشطة التعليمية الملائمة للطلبة، لتحقيق الأهداف التربوية المنشودة. ع - دعم الثقة بالنفس للمتعلمين نحو ميادين المعرفة المتتوعة . 0- مساعدة المتعلمين علي اكتثاف القضايا المهمة . צ- تشجيع الطلبة علي حل المشكلات. أهمية التعلم النشط :

1- يجعل الطالب نشطاً وإيجابياً، ويتيح له الفرص للششاركة ، ويوفر له قدراً من الاستقلالية مما يعوده علي تحمل المسئولية والاعتماد علي ذاته ، فيصبح قادراً علي تنظيم حياته والتخطيط لمستقبله. 1-يحث التعلم النشط الطالب علي التفكير بنفسه، والتعاون علي الحوار مع زملائه ومعلمه r- وذلك لحل المشكلات وممارسة الأعمال الاستقصائية وصولاً للأهداف المنشودة . 
r- يوفر للطلاب بيئة ثرية مليئة بمواقف التحدي التي تحثهم علي التفكير والمشاركة الفعالة

ع- والإيجابية والإصرار علي تحسن أدائهم، وإثراء خبراتهم. 0- يساعد علي تكيف الطلاب مع متطلبات بيئة التعلم البنائة النشطة بما يحويه من استراتيجيات معرفية وما وراء معرفية تعين على التكيف .

\section{أسس التعلم النشط:}

هناك مجموعه من الأسس التي يقوم عليها التعلم النشط يمكن تلخيصها فيما يلي : 1. اشراك الطلبة في اختيار نظام العمل وقواعده . r.اشراك الطلبة في تحديد الأهداف التعليمية .

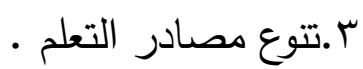

ء.استخدام استراتيجيات التدريس المتمركزة حول الطلبة، والتي تتناسب مع قدرته واهتماماته وانماط تعلمه والذكاءات التي يتمتع بها . عناصر التعلم النشط

كما هناك مجموعه من العناصر التي يقوم عليها التعلم النشط يمكن تلخيصها فيما يلي :

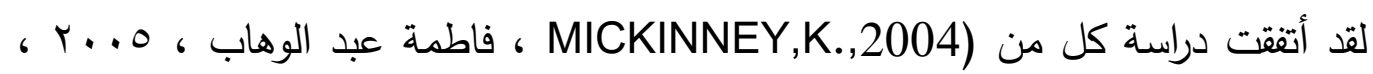

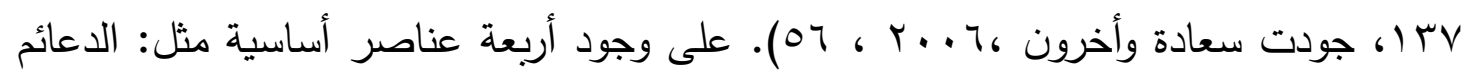
المهمة لاستراتيجيات التعلم النشط وتتمثل هذه العناصر في الآتي :

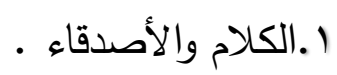

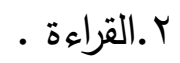

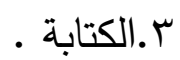

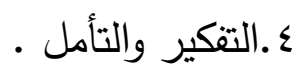

استراتيجية التعلم التعاوني :

ويعتبر التعلم التعاوني نموذجاً وسطاً بين التعليم الجماعي الذي يتحمل فيه المعلم عبء التدريس لمجموعة كبيرة غير متجانسه من الطلاب، وبين التعلم الفردي الذي يدرس فيه المتعلم 
وفقا لقدراته واستعداداته، ويراعي فيه الفروق الفرديه بين الطلاب وفي التعلم التعاوني يهتم المعلم

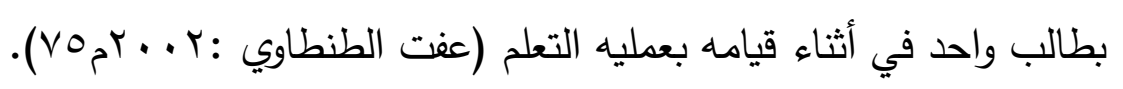
كما إن استخدام التعلم التعاوني في العمليه التعليميه يعتبر من المستحدثات التقنيه التربوية

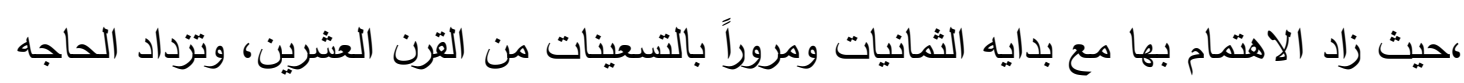
إليه علي أساس مصداقيه إسهامات التعلم التعاوني في تحقيق الأهداف التربوية المرغوب فيها

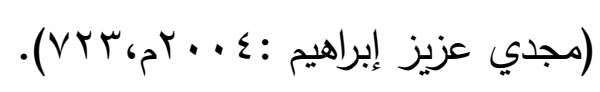

وقد أعلن "جون ديوي" عن مجموعات التعلم التعاوني حينما أشار إلى أن التفاعل الاجتماعي،مهم للتعليم نظرآ لوجود وظائف معرفية عليا مثل قدرة: الفرد علي التفكير وإبداء الرأي

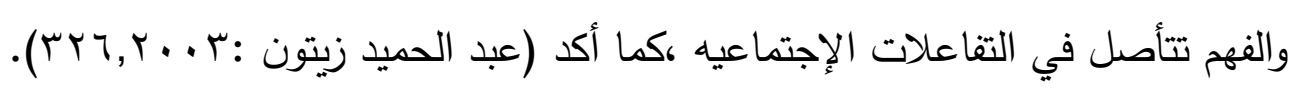
والتعلم التعاوني يقوم على أساس تقسيم الطلاب إلى مجموعات صغيرة غير متجانسة حيث تضم كل مجموعة طلاب قدراتهم مختلفة، وتتكون كل مجموعة من (r-V) طلاب، ويتم توزيع المهام على الطلاب وتبادل هذه المهام فيما بينهم، ويكون لكل مجموعة قائد، ويكون دور

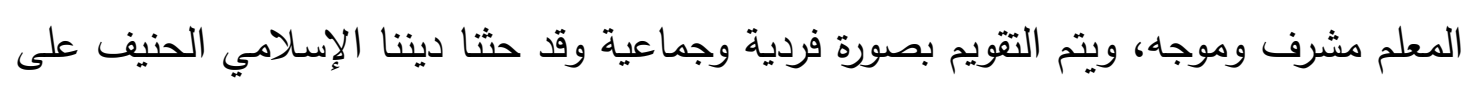

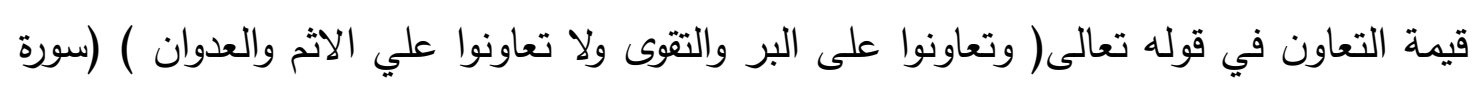

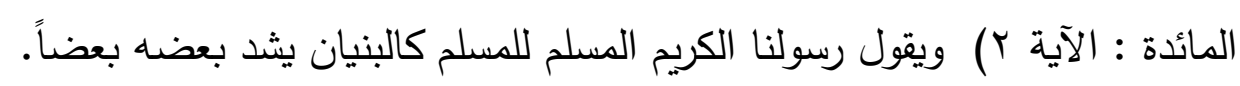

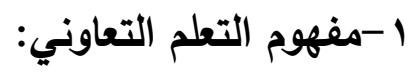

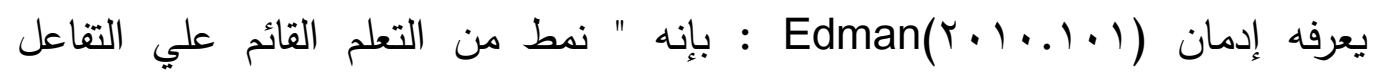
إلاجتماعي بين المتعلمين في مجموعات صغيرة، في مجموعات صغيرة يتشاركون تحقيق أهداف واستراتيجية تعليمية مشتركة من خلال أنشطة جماعية مخططة ومنظمة باستخدام أدوات التواصل لئل عبر الويب وخدماتها ويركز علي توليد المعرفة وليس استقبالها من خلال نشاط المتعلم وتوجيهات المتعلم وإرشاداته" .

وتعرفه الباحثه إجرائياً: نظام تعليمي يتيح عملية التفاعل والمشاركة بين أفراده باستخدام

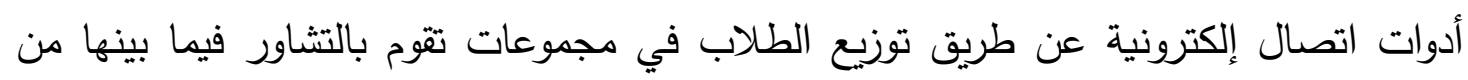
أجل انجاز الاستراتيجية التعليمية داخل بيئة تعليمية شاملة.

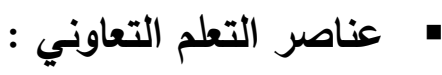


يعرفها "ستين وأريف" (Cetin and Arif(2010,118: على أنها: " مصادر إلكترونية يمكن إعادة استخدامها بهدف تحقيق أهداف التعلم". من خلال ما سبق يمكن تعريف التعلم التعاوني إجرائياً بإنه: طريقة يتم فيها تقسيم الطلاب إلى مجموعات صغيرة تتكون من (r-0) طلاب، ثم يتم تقسيم المادة المراد تعلمها وتوزيعها

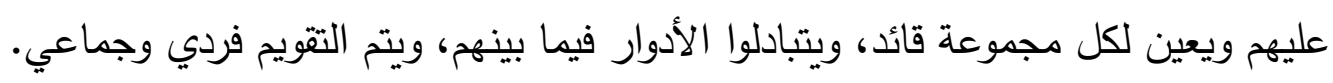

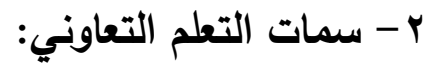

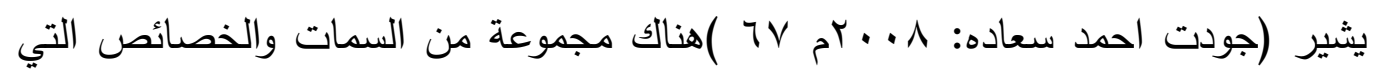
يتميز بها التعلم التعاوني وهي أحد استراتيجيات التعلم والتعليم الفعالة المعاصرة يعتبر الطالب

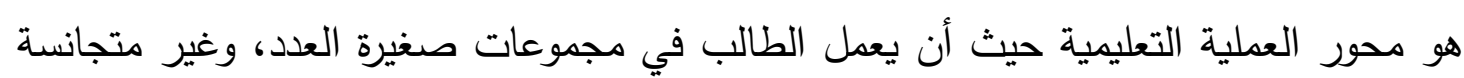
في قدراتها وميولها واهتماماتها حيث أن تفاعل الطلبة في هذا النوع من التعلم هو تفاعل إيجابى متبادل أهداف المجموعة من خلال تطبيق التعلم التعاوني لأهداف مشتركة. فالطالب في المجموعة مسئول عن تعلمه وتعلم أقرانه.

ويتضمن هذا النمط من التعلم اساليب الحوار والمناقثة وحيث يقتصر دور المعلم على لى التوجيه والإرشاد والمراقبة والتعزيز ونتاجات التعلم في هذا الأسلوب يتمثل في تتمية مهارات إجتماعية وشخصية متتوعة وإيجابية. r- مميزات التعلم التعاوني:

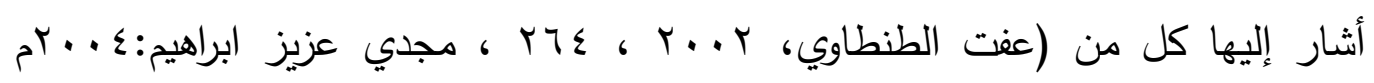

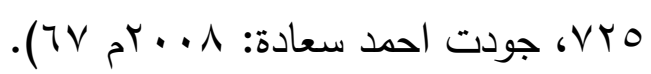
ويمكن تطبيقه في مختلف المراحل الدراسية بدءاً من رياض الأطفال، وحتى مرحلة التعليم العالي، وذللك للمميزات التالية : ا . يساعد على فهم واتقان ما يتعلمه الطلاب من معلومات ومهارات. r. ينمي قدرة الفرد على حل المشكلات وتطبيق ما يتعلمه في مواقف جديدة.

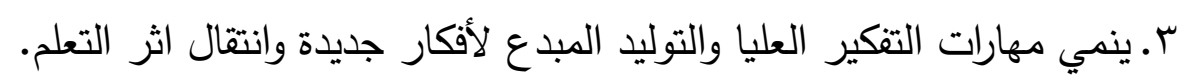
ع. يودي بدوره إلى تتمية المهارات الاجتماعية لدي الطلاب والعلاقات الإيجابية بينهم. ه. يحد من الإحساس بالخوف والقلق الذي يصاحب عملية التعلم. 
7. ينمي المسئولية الفردية، حيث يستند إلى المتعلم بعض الأدوار ويسأل عليها ويراقب من

قبل المتعلم، ولذلك ينمي لديه المسئولية الفردية.

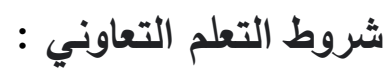

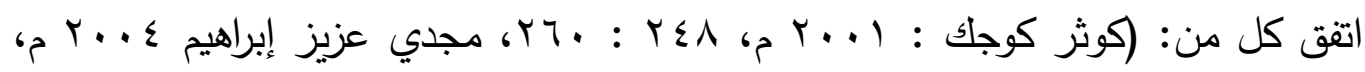

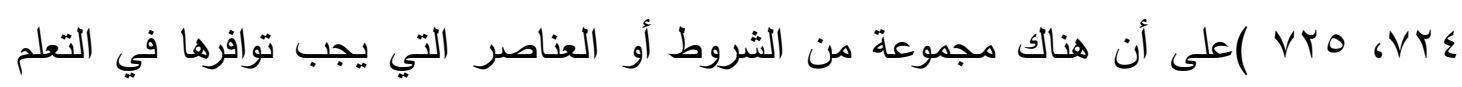
التعاوني وهي:

أ-الاعتماد الإيجابي المتبادل: Positive Inter Dependence :

يقصد به: أن الطالب يجب أن يدرك أن نجاحه معتمد على نجاح المجموعة بمعنى إنه لا لإني

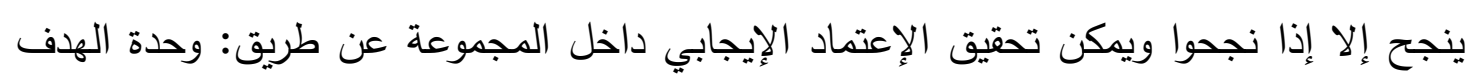
والمكافاة الاجتماعية والمشاركة في الموارد وتحديد أدوار أفراد المجموعة. ب-المحاسبية الفردية: Individual Accountability وتتمثل في أن كل عضو مسئول عن تعلمه للمهة المكلف بها، وأيضاً تعلم زملائه لهذه

المهمة ويتم التحقق من مسئولية الفرد نحو تعلمه الثخصي من خلال الأساليب التالية : - إعطاء اختبار فردي لكل طالب في المجموعة التعاونية يكثف مدى إتقان كل منهم لما تعلمه،

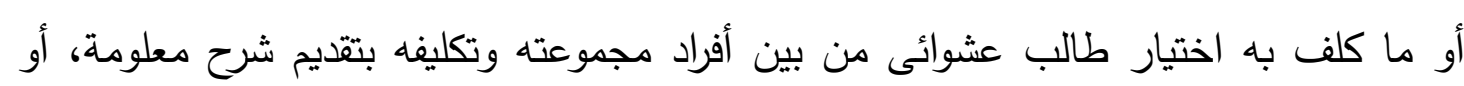
عرض مهارة.

ج _التفاعل المباشر وجهاً لوجه Face To Face Interaction ويقصد به أن يكون أعضاء المجموعة في وضع يسمح لهم بالحوار والمناقشة بسهولة ويسر حتى يستطيعوا التفاعل مع بعضهم، ولكي يتم ذلك لابد على المعلم القيام بالتالى: - تقديم المساعدة والدعم الأكاديمي والثخصي مع بعضهم. - ت تبادل المصادر والمعلومات فيما بينهم.

د-مهارات العمل الجماعي Collaborative Skills ويقصد بها: أن تتفيذ الدرس التعاوني يتطلب تدريب التلاميذ علي مهارات العمل بايجابيه وفاعليه وهذه المهارات هي مهارة التشكيل، مهارة العمل، مهارة الصياغة، مهارة التخمر، 
ولابد من توافر قدر من هذه المهارات والقدرة علي استخدامها لدى أفراد المجموعة قبل انخراطهم في التعلم التعاوني. هـ_برمجة المجموعة معالجة عمل المجموعة Group Processing : ويقصد به مناقثة اسلوب عمل المجموعة بعد الانتهاء من الدرس ( المهمة، أو التكليف ) لتحديد العوامل التي ساعدت المجموعه، أو التي حالت دون تحقيق العمل لأهدافه، وتتم من خلال اساليب عديدة منها: قيام أعضاء المجموعة بمناقشة مفتوحة لما تم إنجازه، ويتم تسجل ذلك في تقرير ، وتتم هذه المناقثة خلال الخمس دقائق الأخيرة من جلسة (درس) التعلم التعاوني. قيام المعلم، أو أحد طلاب المجموعة المراقب بملاحظة مباشرة لأداء المجموعة أثناء قيامها بالعمل وتسجيل الأخطاء أو السلبيات في نقاط. צ- أنواع التعلم التعاوني:

نجد أن التعلم التعاوني يقوم في أساسه على تقسيم الطلاب إلى مجموعات صغيرة تحتوي على عدد من الطلاب فقد قام (عبد الوهاب كوران، (... ، 170 :77 17) بتقسيم مجموعات التعلم التعاوني إلى مجموعات متجانسة: وهي تلك المجموعات التي تضم أفراد متساويين، أو متقاريين في المستوى المعرفي ومستوى القدرات، أو المهارات والميول والرغبات، ويتم تشكيلها لفترات قصيرة بمعيار الفروق الفردية بين الطلاب

$$
\text { ومجموعات غير متجانسة : }
$$

وهي تلاك المجموعات التي تضم أفراد غير متساويين في المستوى المعرفي ومستوى القدرات أو المهارات والميول والرغبات.

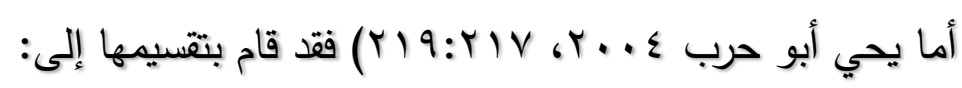

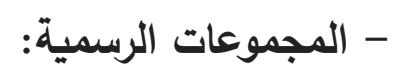


وهي مجموعات تدوم من حصة صفية واحدة إلي عدة أسابيع، ويعمل الطلاب فيها معاً

لإنجاز مهمة محددة والتأكد من أنهم وزملائهم في المجموعة، قد أتموا بنجاح المهمة التعليمية

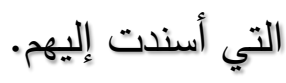

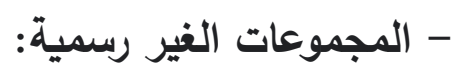

وهي مجموعات ذات غرض خاص، تدوم في بضع دقائق إلى حصة صفية واحدة ، ويستخدم هذا النوع أثناء التعلم المباشر ويشترك الطلاب في مناقثات مركزة، قد تستغرق من ثلاث إلى خمس دقائق، قبل وبعد موضوع الدرس، وكذلك يشتركون في مناقشات مركزة تستغرق المدة الزمنية نفسها على نحو موزع طوال الحصة، أو العرض. المجموعات التعاونية الأساسية: وهي مجموعات طويلة الأجل وغير متجانسة وذات عضوية ثابتة وغرضها الرئيسي تقديم العون والدعم والمساندة والتشجيع الذي يحتاجون إليه، وهي قد تدوم سنة على الأقل، وربما تدوم حتى ينتهي الطلاب من دراستهم استراتيجية التعلم الذاتي: - n يحقق التعلم الذاتي لكل متعلم تعلماً يتناسب مع قدراته وسرعته الذاتية ويعتمد في ذللك على دافعيته، كما يأخذ المتعلم فيه دوراً ايجابياً ونشيطاً، إضافة إلى أن التعلم الذاتي يمكن المتعلم من إتقان المهارات الأساسية اللازمة لمواصلة تعليم نفسه بنفسه ويستمر معه مدى الحياة، وتدريبه على حل المشكلات لإعداده للمستقبل وتعويده تحمل المسؤولية بنفسه وايجاد بيئة خصبة للإبداع وخاصة وأن العالم يشهر انفجاراً معرفياً منطوراً باستمرار لا تستوعبه نظم التعلم وطرائقها مما يحتم وجود إستراتيجية تمكن المتعلم من إتقان مهارات التعلم الذاتي ليستمر تعلمه الذاتي بنفسه.

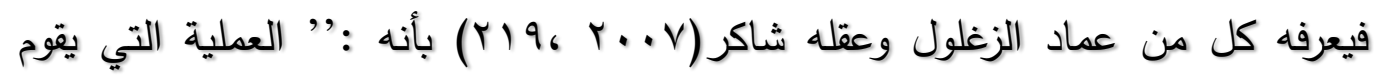
المتعلم من خلالها باكتساب المعارف والخبرات بنفسه، حيث يقع على عاتقه الدور الأكبر في عملية التعلم، فهو يتفاعل مباشرة مع المواقف المختلفة من أجل اكتساب الخبرات والمعارف 
والمعلومات، وتطوير مهاراته وقدراته. وبهذا المنظور فإن عملية التعلم تصبح موجهة نحو المتعلم، فهو محورها الرئيسي وهو الذي يتحمم بمتغيراتها وظروفها، مما يمكنه من السيطرة على مواقف التعلم المختلفة واكتساب الخبرات حسب سرعته الخاصة بما يتلاءم مكاناته". كما تعرفه لويزة مسعودي عن جيلس: " (Gleason) بأنة :" نظام تعليمي، بيير للمتعلم القيام بدراسة بختارها، بحيث يكون فيها متحرراً من قيود الزمان والمكان، والإلتزامات التي تترض عادة في التعليم التقليدي، ويمكن أن يتم نلك بإثراف المعلم، أو بدونه" مسعودي، ـ ( ب.، 9 (Y).

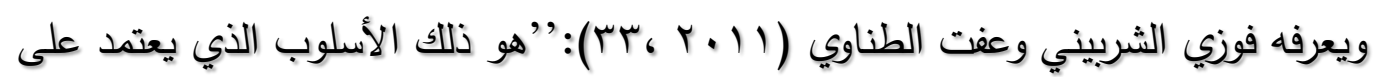
نشاط المتعلم حيث يمر من خلاله ببعض المواقف التعليمية ويكتسب المعارف والمهارات بما يتوافق مع سرعته وقدراته الخاصة، منطلقاً من رغبته الذاتية وقناعته الداخلية ومستجيباً لميوله واهتماماته، ومعتمداً على نفسه، وواثقاً في قدراته، بما يحقق تنمية شخصيته وتكاملها و والتفاعل الناجح مع مجتمعه، ويمكن أن يستخدم المتعلم في أثناء ذللك مواد ووسائل تعليمية متعددة، ومواد مبرمجة، وغيرها من البدائل التعليمية.

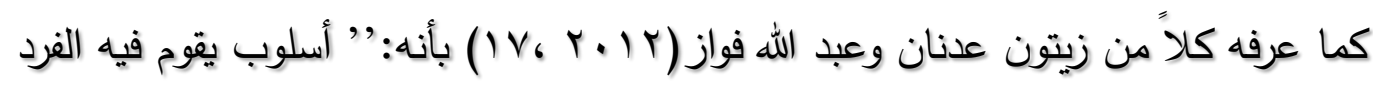
نفسه بالمواقف التعليمية لاكتساب المعلومات والمهارات، بحيث ينتقل محور الإهتمام من المعلم إلى الدتعلم فالمتعلم هو الذي يقرر متى وأين ينتهي، وأي الوسائل يختار، ومن ثم يصبح هو المسؤول عن تعلمه وعن صناعة تقدمه الثقافي والمعرفي وعن النتائج والقرارات التي

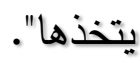
خصائص و مميزات التعلم الاتاتي: من خلال ما سبق عرضه من مفاهيم التعلم، ومن خلال ما ورد من خصائص اللتعلم الذاتي عند

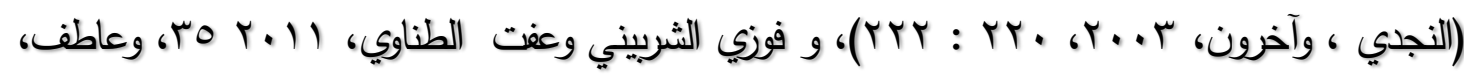

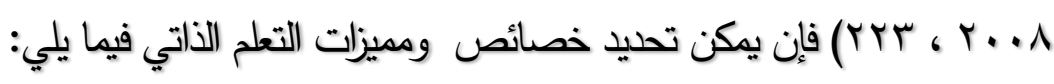


-مراعاة الفروق الفردية بين المتعلمين من حيث قدراتهم على التعلم واهتماماتهم ودافعيتهم

للتعلم ومستوى تحصيلهم وخبراتهم السابقة.

-المتعلم هو الذي يقرر متى وأين يبدأ ومتى ينتهي وأي الوسائل والبدائل يختار .

-المتعلم هو المسؤول عن تعلمه وعن النتائج التي يحققها والقرارات التي يتخذها.

-ما يميز التعلم الذاتي عن الأساليب التقليدية مناسبته لجميع الطلاب وجميع المستويات

والتعلم حسب القدرة الذاتية.

-في التعلم الذاتي تعتبر حاجات المتعلم ورغباته وقدراته واهتماماته أساسا يتقرر في

ضوئها طبيعة المنهج الدراسي ومحتواه.

$$
\text { مبررات التعلم الذاتي: - n }
$$

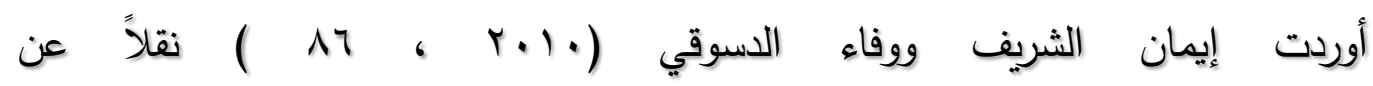

زيمرمان (Zimmerman) أن أهية التعلم الذاتي تكمن في تتمية مهارات التعلم مدى الحياة الذي يعد ضرورة لملائمة طبيعة عصر يتسم بالتغير السريع نتيجة للتدفق المعرفي والتقدم العلمي والتكنولوجي بما يحتم على الفرد ضرورة الاهتمام بتعليم نفسه بنفسه، وأن يمنح الفرصة لكي يختار ويحدد ويتحمل مسئولية ما يود تعلمه بحيث يصبح موجها لذاتة متفاعلاً إيجابياً. مبادئ التعلم الذاتي:

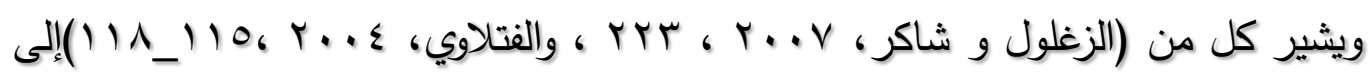
المبادئ التي يقوم عليها التعلم الذاتي كما يلي: ــل متعلم يعد فريداً في سماته وخصائصه رغم تشابهه مع الآخرين فالتعلم الذاتي يراعي الفروق الفردية بين الأقراد من مختلف الأعمار، أو من نفس الفئة العمرية ولدى الجنسين في التعلم والاكتساب. ــمراعاة السرعة الذاتية للتعلم، حيث تهتم برامج التعلم الذاتي بإمكانية تعلم كل تبعا لقدراته الخاصة وامكاناته و سرعته الذاتية، إذ يتيح لهم الحرية والوقت الكافيين للانتقال خطوة خطوة خلال عمليات التعلم والاكتساب دون تدخل من قبل المعلم . 
_التفاعل الايجابي بين المتعلم والموقف التعليمي، حيث يكفل التعلم الذاتي المشاركة الايجابية للمتعلم خلال عملية التعلم، فهو ليس مستقبلاً سلبياً للمعلومات وإنما مشارك فعال في هذه العملية من حيث التخطيط لها وتتفيذها وتحديد مصادرها وتقويم نتائجها. ـيضمن التعلم الذاتي تنويع مصادر التعلم لتشمل الكتب والنشرات والمجلات والأفلام والمصادر التعلم الالكتروني.

ـيحقق التعلم الذاتي ، الفرصة للمتعلمين بالسيطرة والتحكم في مواقف التعلم واخضاعه لإرادتهم وفق قدراتهم وامكانياتهم الخاصة، فالمتعلم لاينتقل من موقف تعليمي إلا بعد تعلمه

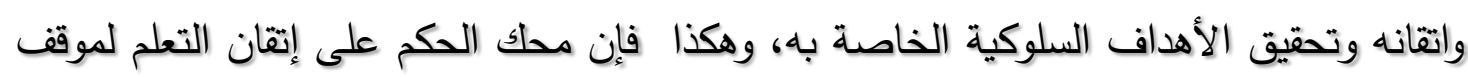
ما يتمثل في انجاز الأهداف والنتاجات المرتبط. به ـ التغذية الراجعة والتعزيز الفوري للمتعلم، حيث يؤكد التعلم الذاتي على أهمية الإعلام الفوري للمتعلمين بنتائج تعلمه ومستوى إتقانهم للمهمات التعليمية حول نجاحهم، أو فشلهم، بالإضافة إلى التعزيز الفوري المناسب للانجاز الذي يحققونه أثناء عملية التعلم . - زيادة الدافعية الذاتية للمتعلم، حيث يعمل التعلم الذاتي على تثجيع المتعلمين وتحفيزهم أثناء عملية التعلم فيجعل منهم أكثر فاعلية وايجابية في التعامل مع المواقف التعليمية المختلفة، من خلال خبرات التغذية الراجعة والتعزيز التي يتلقونه أثناء عملية التعلم، وهذا ما يؤدي إلى زيادة الرغبة لدى المتعلمين في متابعة عمليات التعلم والاستمرار به( التعليم المتتمر). - التوجه الذاتي للمتعلم، حيث يشجع التعلم الذاتي المتعلم على التخطيط واتخاذ القرارات المناسبة حول مواقف التعلم وبالتالي اختيار طرائق التعلم والأنشطة التي تتلاءم مع إكاناته وقدراته، مما ينمي الاستقلالية الذاتية لديه. ــمولية التقويم واستمراريته ، حيث يعتمد التعلم الذاتي على جهود المتعلمين الفردية ما، يعني أن هناك مراجعة مستمرة ومتواصلة لعملية التعلم لديهم، ومثل هذه المراجعة تنطوي على تقييم التقدم الذي يتم إحرازه في التعلم بالإضافة إلى تقييم طرائق التعلم ومصادره المتنوعة. أساليب التعلم الذاتي: - n 
لقد كان لحركة تعربد التعليم والجهود التربوية المنظمة دور كبير في ظهور مجموعة كبيرة من الاستراتيجيات التربوية الخاصة بتصميم برامج تتفق وأساليب التعلم الذاتي، وتتصف بقدرة كبيرة على تثربد التعليم، وبالرغم مما قد يوجد من تباين بين هذه الاستراتيجيات والأساليب، فإنها جميعا تتفق في تحقيق تعلم يؤكد ايجابية المتعلم، وبما يتناسب مع قدراته واحتياجاته ويراعي خصائصه الفردية، ومن اساليب التعلم الذاتي :أسلوب الموديول (الوحدة التعليمية)، الحقيبة التعليمية (الرزم التعليمية)، التعلم المبرمج.

المحور الثاني · بيئة التعلم الاكتروني:

أصبحت عملية التعلم لا تقتصر فقط على اكتساب المعرفة، إنما أيضًا بناءها وتطويرها للمعرفة اجتماعيًا وثقافيًا، ومن خلال التأكيد على مفهوم التعاون والتشارك بين الطلاب والربط بين خبراتهم. (حسناء الطباخ، \& 9، ع ا ـ r). مفهوم التعلم الإكتروني E-Learning :

إن التطور الهائل في تكنولوجيا الاتصالات والمعلومات أنعكس ذلك بشكل كبير علي منظومة التعليم والتعلم الإلكتروني ، وتعددت الآراء حول ماهية التعلم الإككترني ومنها :

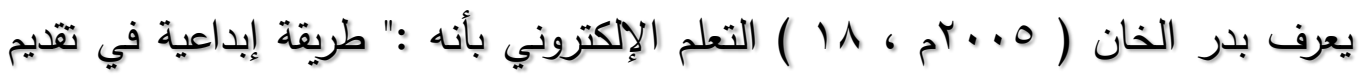
بيئة تفاعلية، متمركزة حول المتعلمين ، ومصممة مسبقاً بشكل جديد ، وميسرة لي فرد ، وفي أي مكان، وأي وقت بأستعمال خصائص ومصادر الإنترنت والتقنيات الرقمية بالتطابق مع مبادئ تصميم المواقف التعليمية المناسبة لبيئة التعلم المفتوحة / والمرنة ، والموزعة ". أهداف التعلم الإلكتروني:

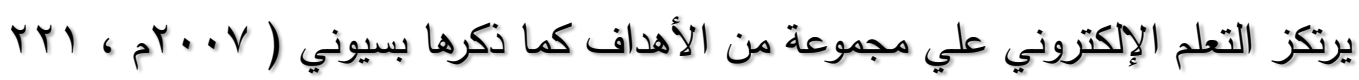
) حيث يسعي إلي تحقيق الأهداف التاليه :

- تمكن الطالب من التفاعل معها بكفاءة ومواكبة التطورات . 
- إمكانية الإتصال بين الطلبة فيما بينهما ، وبين الطلبة والمدرسة بفاعلية. - توفير المقررات طوال اليوم وعلي مدار الأسبوع. - تقديم التعلم في صورة نموذجية والأستغلال الأمثل لتقنيات التعليم - سهولة وتعدد طرق تقييم الطالب بصورة سريعة وسهلة التقييم.

- تخفيف الأعباء الإدارية علي المعلم والإدارة مثل: الواجبات وتصحيح الأختبارات ورصد الدرجات.

ب-أهمية التعلم الإلكتروني :

للتعلم الإكتروني أهمية كونه النموذج الجديد الذي غير التعليم التقليدي في المؤسسات التعليمية ، لتدريب المتعلمين في جميع المجالات التعليمية والعلمية، وتتضح الأهمية كما ذكرها إسماعيل ( 9 . . rم ، 9هـ ) في النقاط التالية : يتعلم الطالب بصورة فردية حسب قدراته الخاصة وفي الوقت المناسب له.

يتحكم المتعلمين في عمليات التعلم، منا يتولد لديهم دافعية للتعلم يحث المرونة في بيئة التعليم، ومراعاة أساليب التعلم المختلفة.

ينقل التعلم من قاعة الدروس إلي الجيب ، حيث تمكن المتعلمين تنفيذ المواقف التعليمية في أي مكان، ومن ثم يمكنه من الإستفادة من الوقت وعدم إهداره فيما يسمي بالتعلم النقال . يشجع المتعلم علي إدارة تعامله وبالطريقه التي تناسبه .

يصبح المتعلم أكثر تفاعلاً مع البرنامج مع تركيز جميع حواسه بالخبرات المكتسبة والمتعلمة، لكي تجعل المتعلم أكثر دافعية وكفاءة أثناء التعلم . ع-مميزات التعلم الإككتروني : 
هناك العديد من المميزات التي يتميز بها التعلم الإكتروني عن غيره من أنواع التعلم

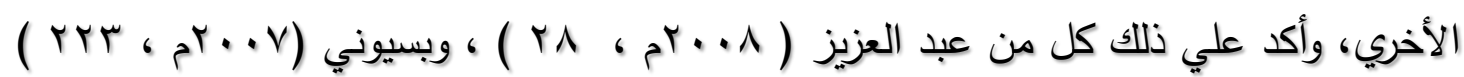
في النقاط الآتيه:

$$
\text { - - المرونة في التفاعل مع المحتوي الدراسي. }
$$

- سهولة الأنتقال لأماكن التعلم أي يمكن التعلم في أي وقت وفي أي مكان علي مدار

$$
\text { ساعات أيام الاسبوع · }
$$

- السهولة والاقتصاد في تطوير وتعديل مجتيو المادة الدراسية.

- السرعة في التفاعل مع محتوي المادة الدراسية.

- زيادة الاحتفاظ بالتعلم وذلك لأستخدام وسائل تعليمية سمعية بصرية.

- توفر محتوي علمي ومعلومات حديثة من خلال برامج الإتاحة والتصفح الإكترونية . - تنمية القدرات الفكرية وإثراء مستوي التعلم.

المحور الثالث : عناصر التعلم الرقمية :

ويُعد مصطلح " عناصر التعلم الرقمية " بمثابة امتداد لمصطلحي الوسائط المتعددة

Digital learning Objects والفائقة، حيث يمكن تعريف مصطلح عناصر التعلم الرقمية بأنها :أجزاء تعليمية صغيرة (مكونة من مقاطع الصوت والفيديو والصور الثابتة والمتحركة والنصوص) مخزنة داخل مكان محدد يسمى مستودعا رقميا، ويمكن استرجاعها والاستفادة منها وإعادة استخدامها مرة أخرى، كما أن كلمة “عنصر” تشير إلى أنها أبسط صورة للمادة ولا يمكن تحليلها إلى صورة أبسط منها كما ورد في تعريف العنصر. وقد تطور مفهوم عناصر التعلم تطوراً كبيراً منذظهوره في عام ب99 19 وحتى الآن، ويرجع النطور في المفهوم إلى: تطور البيئات التعليمية مع زيادة استخدام شبكة الإنترنت والاعتماد على التعلم الرقمي.

أهداف عناصر التعلم الرقمية: - (المية

$$
\text { المجلد السابع- العدد الثاني- مسلسل العدد (14)- يوليو 2021- الجزء الأول }
$$


سهولة الوصول إليها :طالما أن هذه العناصر يمكن نشرها وتحميلها على الإنترنت، ومن هنا سيسهل الوصول إليها وتوظيفها في مواقف تعليمية مختلفة كالتالي : - التوظيف وإعادة الاستخدام :من المكن إجراء بعض التعديلات البسيطة على محتوى عنصر من عناصر التعليم وبالتالي يمكن إعادة استخدامه في موقف تعليمي آخر. - الملاعمة :يمكن تغيير بعض خصائص عنصر التعلم من حيث اللون والحجم ونوع الخط وحجمه حتى تتناسب مع الموقف التعليمي. - التفرد :بمعنى أنه يمكن تشغيل هذا العنصر مباشرة بدون استخدام أي برامج لتشغيله أو فتحه.

- التفاعل :وهو من أهم خصائص عُصر التعلم، حيث تسمح هذه الخاصية للمتعلم بالتفاعل مع عنصر التعلم عن طريق السحب والإفلات أو وضع إطار حول الصورة أو كتابة تعليق عليها، فالمتعلم نشط ومتفاعل.

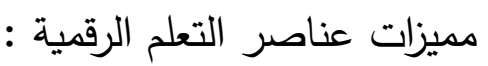

- مساهتها في تحسين عملية التعلم. - احتواء عنصر التعلم على النص والصوت والصورة قد يساعد في جذب انتباه الطلاب وزيادة دافعيتهم للتعلم.

- قلة التكلفة: فمن المكن تصميم وإنتاج صورة تعليمية واحدة تصلح لمواقف تعليمية مختلفة.

المرونة: إمكانية التعديل على عنصر التعلم متوفرة بما يتناسب مع المواقف التعليمية ومع طبيعة المتعلمين، حيث يمن استخدام نفس العنصر مع مجموعة من ذوي الاحتياجات الخاصة بإجراء تعديلات بسيطة عليه. - تساعد الطلاب على تنمية التفكير والتخيل والتحليل والاستنتاج من خلال المحتوى الذي يعرض عليهم.

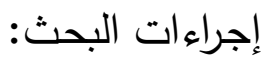


تم تنفيذ إجراءات البحث من خلال :

أولاً: تصميم وتطوير مادة المعالجة التجريبية.

ثانياً: إعداد أدوات البحث المتمثلة في (قائمة معايير/ قائمة مهارات/ اختبار تحصيلي/

بطاقة ملاحظة).

ثالثاً: التجربة الإستطلاعية.

رابعاً: التجربة الأساسية.

أولاً: تصميم وتطوير مادة المعالجة التجريبية: .

تم تصميم بيئة التعلم الاكتروني القائمة على استراتيجية التعلم النشط وفقاً للنموذج العام ADDIE ، بحيث تحتوى على بعض المهارات المستخدمة في التعلم التعاوني لتحقق التشارك بين الطلبة في أداء الاستراتيجية المطلوبة وفيما يلى عرض لمراحل التصميم التعليمي المتبع: - n

المرحلة الأولى : مرحلة التحليل :

ا. تحليل خصائص الفئة المستهوفة وسلوكهم المدخلى: يهدف تحليل خصائص المتعلمين إلى التعرف على أهم الخصائص المتوفرة لدى الفئة المستهدفة العقلية والاكاديمية والنفسية والأجتماعية، وبالتالي يجب مراعاة حاجاته وميوله وقدراته واهتماماته، والفروق الفردية بينه وبين زملائه، وأنه يوجد تجانس بين أفراد العينة من حيث العمر الزمني والعقلي والبيئة المحيطة. r. اختيار الفئـة المستهدفة (العينـة): قامت الباحثة بإختيار عينة البحث من طلاب الفرقة الثالثة شعبة تكنولوجيا التعليم قسم تكنولوجيا التعليم بكلية التربية النوعية - جامعة الزقازيق حيث يدرس لهم مقرر الوسـائط المتعددة، وفيها يتعلمون إنتاج عناصـر التعلم الرقميـة المختلفة، وقامت الباحثة بإختيار عينة عددها ( ـ ؟) طالب فقط من طلاب الفرقة، مما توافر لديهز إمكانيات الدخول على موقع بيئة التعلم الالكتروني من وجود شبكة إنترنت، وقيامهم بتثبيت البرامج اللازمة وأدائهم للانشطة المطلوبة. 
r. تحليل الموارد وإلقيود فى بيئة التعلم: في هذه المرحلة قامت الباحثة بتحليل عدة عناصر للوقوف على الموارد والقيود الموجودة فى بيئة التعلم وهى بشرية حيث تم اختيار عينة البحث من قسم تكنولوجيا التعليم شعبة إعداد معلم الحاسب آلى على أسـاس إجـادتهم لمهارات استخدام الحاسب والانترنت، من خلال موقع عبر الشبكة يوفر استضافة موقع بيئة التعلم الاككتروني واستخدام متصفحات الويب ذات اعتمادية عالية، تحملت الباحثة وحدها التكلفة المادية كاملة ولا يقع أى جزء منها على الطالب، حيث تمت الدراسة على الأجهزة الثخصية للطلاب فلا وجود مكان محدد، زمانية حيث يتم الدخول إلى الموقع فى أوقات تناسب الطلاب ولا تتعارض مع أوقات دراستهم بالاتفاق مع الباحثة. ع. تحليل مهمات التعلم: تتمثل في تحليل المحتوى وتحديد كل المهارات الرئيسية والفرعية، وتتمثل فى الموضوعات، أوالمفاهيم، أوالمهارات الرئيسية والفرعية فى الموضوع ويمن توضيحه في الخطوات الآتيه: أ. تحليل المشكلة وتحديدها: تم تحديد المشكلة في وجود فجوة بين مستوى الأداء الحالى ومستوى الأداء المطلوب لدى الطلاب في مهارات لتصميم عناصر التعلم الرقمية، ويتم التغلب عليها فى البحث الحالى باستخدام بيئة تعلم تعاوني قائمة على استراتيجية التعلم التعاوني، لكى نصل إلى النمط الانسب لتنمية مهارات لتصميم عناصر التعلم الرقمية، وقد حددت الباحثة العوامل التى استخلصت منها مشكلة البحث في الاحساس بالمشكلة سابقاً. ب. تحديد الأهداف التعليمية: تم إعداد قائمة الأهداف في صورتها المبدئية، وقامت بعرضها علي مجموعة من المحكمين المتخصصين في مجال تكنولوجيا التعليم ، وذلك بهدف استطلاع رأيهم حيث جاءت جميع الأهداف بالقائمة بنسبة المئوية لتحقيقها للسلوك التعليمي المطلوب أكثر من •^^\%، وبذلك أصبحت قائمة الأهداف في صورتها النهائية ، تتكون من (0) أهداف عامة، و(r^) هدف معرفياً في ملحق (r). 
ج. تجميع المحتوى التعليمي: تم تجميع المحتوى التعليمي للتخطيط لتصميم لعناصر التعلم الرقمية من خلال الأهداف التعليمية في صورتها النهائية، وتم استخلاص المحتوى الذي يغطي هذه الأهداف ويعمل على تحقيقها، ثم قامت بعرضه مع الأهداف الخاصة بـ على

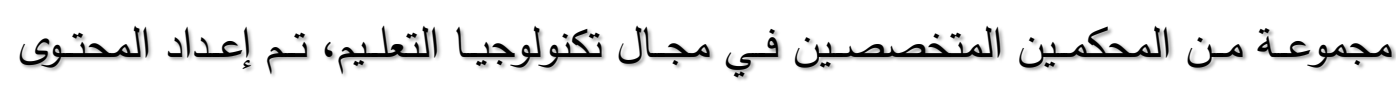
التعليمي في صورته النهائية ملحق ( ؟) تمهيدًا للاستعانة به عند بناء السيناريو الخاص بالبيئة التعليمية. د. تحديد الاستراتيجية الفرعية للمحتوى التعليمي: وتتمثل فى المهارات الرئيسية والفرعية فى الموضوع، وقامت الباحثة فى هذه الخطوة بعمل قائمة بالمهارات الرئيسية للتخطيط لتصميم عناصر التعلم الرقمية في ملحق (ه). المرحلة الثانية : مرحلة التصميم Design: ا. تنظيم المحتوى التعليمى لعناصر التعلم الرقمية: تم تقديم المتوى وعرضسه داخل بيئة التعلم التعاونيـة مـن خـلال عـرض المعلومـات اللفظيـة مـن خـلال النصـوص المكتوبـة ، مصحوبة بالرسوم التوضيحية والصور الثابتة، حيث يتنقل الطالب بين المديولات التعليمية بحرية، وعند الضغط على المديول تظهر عناصره للتجول داخلها، واتبعت الباحثة فى تتظيم عرض المحتوى بطريقة التحليل الهرمى من أعلى إلى أسفل ، حيث يبدأ من أعلى بالمهيات العامة ويندرج لأسفل نحو المهات الفرعية. r. ت تعديد استراتيجيات التعليم المستخدمة: استخدمت الباحثة استراتيجة التعلم التعاوني التي تعد أحد أنواع التعلم التعاوني، وفيها يتم تقسيم المتعلمون إلى ست مجموعات وكل مجموعة تشمل عدد (ه) طلاب، يتشاركون معاً عبر تطبيق (Videonot.es)، و (Evernote) في إنجاز وإرسال التكليفات المطلوبة.

r. تصـيم أنشطة التعلم المناسبة للمحتوى التعليمي:تم تصـميم أنثـطة التعلم للمحتوى الخاص بها في شكل رحلة معرفية تعتمد على المصادر الدلالية، بحيث يضغط المتعلم على زر مكتوب داخله الرحلة المعرفية، فينتقل إليها، وتحتوي الرحلة المعرفية على تبويبات مرتبة 
بشكل رأسي تشمل المقدمة، والمهمة، والعمليات، والمصادر، تقويم، خاتمة، صفحة المعلم، ويضغط المتعلم على التبويب فيظهر محتواه، وعند الضغط على تبويب المصادر يظهر أيقونات المصادر المتاحة مثل تطبيق (Videonot.es) الذي يحتوى على فيديوهات تساعد المتعلم في إنجاز المهمة وتسمح له بالتشارك مي مجموعته وميع الباحثة، ومحرك البحث تساعده في البحث عن أي معلومة. ؟. تحديد أنماط التفاعلات التعليمية : تقوم التفاعلات التعليمية في بيئة التعلم التعاوني على أساس التعلم الفردي في دراسة الدحتوى والجماعي لإنجاز الاستراتيجية التعليمية ، الذي يتفاعل فيه المتعلمون واشتملت البيئة على ثلاث أنماط من التفاعلات هما: التفاعل بين المتعلم المحتوى، والتفاعل بين المتعلمين بعضـهم البعض وبين والباحثة عبر تطبيق وعبـر الاميـل الخـاص بالباحثـة للمحادثـات والاستفسـار (Evernote,Videonot.es) والمناقثات، والتفاعل بين المتعلم والمصادر الدلالية الموجودة بالنشاط. ه. تصميم أدوات تقويم المناسبة: وهي الأدوات التى تركز على قياس الأهداف المعرفية والمهارية للبيئة التعليمية، وتتمثل أدوات القياس فيما يأتى: الاختبار التحصيلي: قامت الباحثة ببناء الاختبار التحصيلي المرتبط بالجوانب المعرفية لمقرر مهارات لتصميم عناصر التعلم الرقمية، وقد بلغ عدد أسئلته (YA) سؤالاً، موزعين على مجموعتين من الاسئلة إحداهما من نوع أسئلة الصواب أو الخطأ وعددها(ب ا) سؤال ، والآخر من أسئلة الاختيار من متعدد وعددها(0 (1) سؤال في ملحق (7). • بطاقة ملاحظة: لقياس الأداء المهارى بمهارات لتصميم عناصر التعلم الرقمية تحتوى على إحدى عشر مهارة.

7. تصميم السيناريوهات : تأسيساً على ما سبق، وفي ضوه قائمة الأهداف التعليمية والمحتوى التعليمي ، تم بناء محتوى السيناريو المبدئى من خلال خمسة أعدة رئيسة هي: رقم الإطار - الجانب المرئى - الجانب المسموع - وصف الإطار - ملاحظات، وبعد الانتهاء من 
صياغة شكل السيناريو الأساسي في صورته المبئية، على ضوء الأسس والمواصفات الفنية والتربوية التي تم تحديدها في ملحق (V). V. تصميم دليل المتعلم: ويشمل دليل المتعلم معلومات حول خطة السير داخل الموقع، ومتطلبات التشغيل، تعليمات الاختبار، وخطة السير داخل الرحلة المعرفية ملحق(^). المرحلة الثالثة : التطوير Development : وتثمل هذه المرحلة الخطوات التالية : ا. إنتاج بيئة التعلم التعاوني: تم الإنتاج الفعلي لبيئة التعلم بالاعتماد على لغة php5 ، actionScript 3، CSS5 Sound في كتابة النصوص وبرنامج Adobe Photoshop 7.0 ME فئع، وبرنامج Camtasia و Forge 7.0 Adobe Adobe Photoshop 7.0 ME أصوبى إلستريتور Illustrator فى إنتاج الصوروالرسوم ، وبرنامج Adobe Flash cs5 و أدوبى أفتر إفكتس Adobe after effect في إنتـاج الصـور والرسـوم المتحركـة ، وبرنـامج Wondershare QuizCreator r. الإخراج النهائي للبيئةة: تم عرض الموقع على مجموعة من المحكمين لإبداء رأيهم فيه، وتم عمل التعديلات اللازمة، بحيث يجهز الموقع للتطبيق التجريبي. المرحلة الرابعة : مرحلة التنفيذ : تضمنت هذه المرحلة الإجراءات التالية: ا. اتاحة بيئة التعلم عبر الإنترنت : وفي هذه المرحلة قامت الباحثة برفع الموقع على أحد الخوادم Servers ، وتم حجز عنوان Domain وهو كالآتي: r. تطبيق بيــة التعلم : تم ذلك بتجريب عناصر التعلم الرقمية على عينـة استطلاعية من المتعلمين قوامها (• ( ) طلاب وذلك لتجريب الموقع والوقوف على أية مشكلات قد تظهر أثناء الاستخدام الفعلي بما يفي تحديد جوانب الضعف لعلاجها ومواطن القوة لتعزيزها. المرحلة الخامسة : مرحلة التقويم : تضمنت هذه المرحلة الإجراءات التالية: 
1. تقويم جوانب التعلم لمحتوى بيئة التعلم: تم تقويم جوانب التعلم المعرفية والمهارية عقب دراسة الطلاب لمحتوى الموقع، وذلك من خلال الاختبار التحصيلي لتقويم الجوانب المعرفية ، وبطاقة ملاحظة لتقويم الجوانب المهارية.

التطبيـق على عينـة البحث الأساسـية: بعد التأكد من صدق وثبات بطاقـة الملاحظـة والاختبار وصلاحية الموقع تم التطبيق على عينة البحث الأساسية.

\section{نتائج البحث وتفسيرها والتوصيات والمقترحات}

تم عرض النتائج التي تم التوصل إليها عن طريق إجراء التجربة الأساسية للبحث ، متبوعة بتحليل تلك النتائج وتفسيرها ، والتعرف على متضمنات النتائج، وكيفية الإفادة منها على المستوى التطبيقس، بالإضـافة إلى تقديم التوصيات، والبحوث والدراسـات المستقبلية المقترحة، وفيما يلي عرضاً تفصيلياً لمعالجة نتائج الاراسة إحصائيا.

في ضوء تطبيق التجربة الأساسية، وتصحيح ورصد درجـات الطلاب في الاختبار التحصيلي ، الذي يقيس التحصيل المرتبط بالجانب المعرفي لمهارات تصميم عناصر التعلم الرقمية، وبطاقة ملاحظة الأداء العملي التي تقيس معدل أداء الطلاب لتلك المهارات، قامت

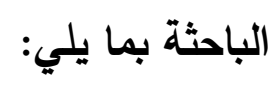
1- اختبار صحة الفرض الأول: والذي نص على:

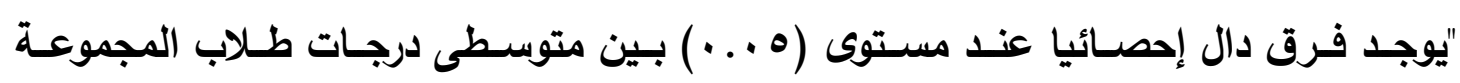
التجريبية الأولى التي درست باستخدام التعلم التعاوني، ودرجات المجموعة التجريبية الثانية التي درست باستخدام التعلم الذاتي فى التطبيق البعدى للاختبار التحصيلى المرتبط بالجوانب المعرفية، لصالح المجموعة التجريبية الثانية" لامبل وللتحقق مـن صحة هذا الفرض قامت الباحثة بالتحليل الإحصـائي لنتائج تطبيق الاختبار التحصيلي لطلاب العينتين: التجريبية الأولى والتجريبية الثانية بعدياً. 
Independent - Samples واستخدمت الباحثة اختبار (ت) لعينتين مستقلتين T.Test ، للتعرف على الفروق بين متوسطات درجات أفراد المجموعتين: التجريبية الأولى، والتجريبية الثانية في التطبيق البعدي للاختبار التحصيلي، وكانت النتائج على النحو التالى:

جدول (1) نتائج إختبار ت Independent - Samples T.Test للفروق بين متوسطات درجات أفراد المجموعتين التجريبية الأولى والتجريبية الثانية فى التطبيق البعدي للاختبار التحصيلي

\begin{tabular}{|c|c|c|c|c|c|c|}
\hline قيمة مستوى الدلالة & قيمة "ت" & الحرية & الإنحراف & الحستوسط & العدد | ل العد & المجموعة \\
\hline \multirow{2}{*}{$\cdots$} & \multirow{2}{*}{$\varepsilon \ldots 19$} & \multirow{2}{*}{01} & T. YV & $\{0 . \leqslant$ & $r$. & تجريبية أولى \\
\hline & & & 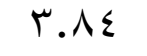 & $\varepsilon \wedge . .7$ & $\mu$. & تجريبية ثانية \\
\hline
\end{tabular}

ويتضح من نتائج جدول ( 1) أن قيمة مستوى الدلالة ( . ... ) أقل من (ه . . ) أي

أنها دالة إحصائياً ، مما يؤكد وجود فرق دال إحصائياً عند (ه ...) بين أفراد المجموعتين التجريبية الأولى والتجريبية الثانية ، في درجات التطبيق البعدي للاختبار التحصيلي، لصالح طلاب المجموعة التجريبية الثانية التي درست باستخدام التعلم الذاتي، الأعلى في متوسط

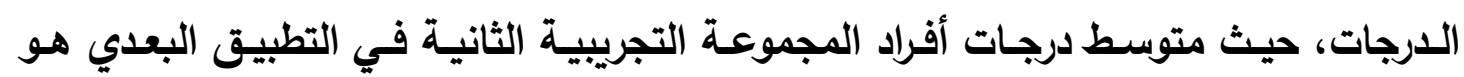

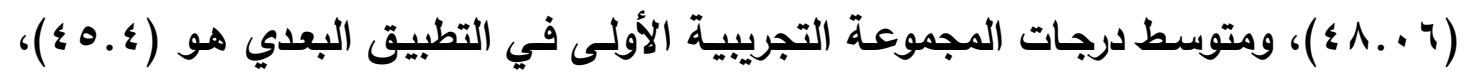
وعلى ذلك يمكن قبول الفرض البحثي الأول للبحث الحالي.

\section{وتريع الباحثة هذه النتائج إلـى}

1- البرنامج تم إعدادة ليتناسب مع حاجات المعلمين .

r- موضوع البرنامج جديد ومشوق للمعلمين فقد ظهرت رغبة لديهم في التدريب.

r-تزويد المعلمين بمهارات واستراتيجيات تطبيقية خلال التدريب .

ع - أتاح التدريب للمعلمين تبادل الخبرات العملية .

0-تزويد المعلمين بمادة مرجعية ومصادر منوعة للبحث والاطلاع والتجديد . 
r- اختبار صحة الفرض الثاني :- والاني نص على :

"يوجــ فـرق دال إحصـائيا عند مستوى (ه . . ·) بـين متوسـطى درجـات طـلاب المجموعـة التجريبية الأولى التي درست باستخدام التعلم التعاوني، ودرجات المجموعة التجريبية الثانية التي درست باستخدام التعلم الذاتي فى التطبيق البعدى لبطاقة الملاحظة المرتبطة بالجانب

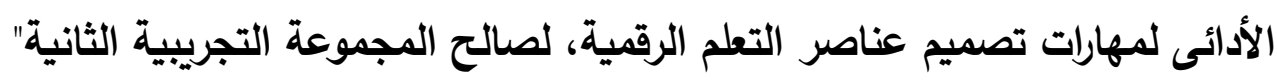
وللتحقق من صحة هذا الفرض قامت الباحثة بالتحليل الإحصائي لنتائج التطبيق البعدي لبطاقة الملاحظة لأفراد العينتين التجريبيتين: الأولى والثانية . Independent - واستخدمت الباحثة أسلوب إختبار (ت) لعينتين مستقلتين Samples T.Test ، للتعرف على الفروق بين متوسطات درجات مستوى الأداء المهاري لمهارات تصميم عناصر التعلم الرقمية لدى أفراد المجموعتين التجريبيتين: الأولى والثانية ، في التطبيق البعدي لبطاقة الملاحظة ، وكانت النتائج على النحو التالى:

جلول (ץ) نتائج إختبار ت Independent - Samples T. Test للفروق بين متوسطات درجات أفراد المجموعتين التجريبيتين: الأولى، والثانية فى مستوى الأداء المهاري لمهارات تصميم عناصر التعلم الرقمية في التطبيق البعدي لبطاقة الملاحظة

\begin{tabular}{|c|c|c|c|c|c|c|}
\hline قيمة مستوى الدلالة & قيمة "ت" & درجات & الإنحراف & الحسابي & العدد & المجموعة \\
\hline \multirow{2}{*}{$. M Y \leq$} & \multirow{2}{*}{. $.99 \varepsilon$} & \multirow{2}{*}{01} & r.Yq & 98.74 & $r$. & تجريبية أولى \\
\hline & & & r.11 & $9 \vee . .7$ & $r$. & تجرببية ثانية \\
\hline
\end{tabular}

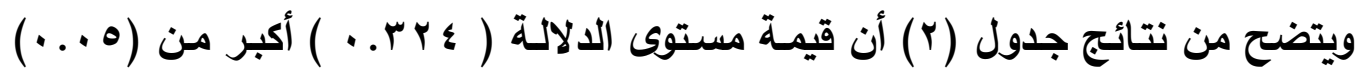
أي أنها غير دالة إحصائياً ، مما يؤكد عدم وجود فرق دال إحصائياً عند (ه . . ) بين أفراد المجمـوعتين: التجريبيـة الأولـى والتجريبيـة الثانيـة، فـي درجـات التطبيـق البعدي لبطاقـة الملاحظة، وعلى ذلك يمكن رفض الفرض البحثي الثاني للبحث الحالي. وتربع الباحثة هذه النتائج إليى : 
1- اعتمد البرنامج التعليمي علي استراتيجيات التعلم النشط في تطبيقه وهي استراتيجيات تخلق جواً من الديمقراطية وحرية التعبير .

r- إتاحة الفرصة للمعلمين بعرض الدروس التعليمية ومناقشتها أمام مجموعة لتطبيق التعليم المصغر. r- محتوي البرنامج مشوق وجديد لدي المعلمين . ع - البرنامج يمس حاجة ملحة لدي المعلم لأنه يربط البرنامج بالمحتوي الذي يحبه كثير من المعلمين والضعف لدي الطلاب في التحصيل الدراسي . ثالثا: توصيات البحث:

في ضوء النتائج التي توصل إليها البحث الحالي ، توصي الباحثة بضرورة السعي نحو تحقيق الأمور التالية :

1- الاهتمام باستخدام استراتيجيات التعلم لدعم التعلم النشط لدي الطلاب في بيئة التعلم الإكترونية.

r- الاهتمام باستخدام تطبيقات المواقع الإكتروني الخاص بالبيئة الإلكتروني التي تعمل

$$
\text { علي تفاعل. الطلاب وتشاركهه. }
$$

r- الاهتمام بالتوظيف الجيد للاستراتيجيات داخل بيئة التعلم الإكتروني ووفقا لأسلوبهم

$$
\text { المعرفي المناسب }
$$

ع- الاهتمام بتنوع مصادر التعلم وأساليب التفاعل في بيئة التعلم الإكتروني . ه- توظيف استراتيجيات التعلم النشط لتتمية العديد من المهارات الإكترونية التي تحتاج إليها التعليم الإكتروني ·

1- الاستعانة بالمهارات التي يمكن استخدامها في عملية تصميم المواقف التعليمية المختلفة.

رابعاً: مقترحات وبحوث مستقبلية:

المجلد السابع- العدد الثاني- مسلسل العدد (14)- يوليو 2021- الجزء الأول 
مجلة دراسات وبحوث التربية النوعية

1- يقترح البحث الحالي إجراء بعض البحوث المقترحة ، كما يلي :

r- - - - إجراء دراسة حول أثر استخدام استراتيجيات التعلم النشط داخل بيئة التعلم الإكتروني

لتنمية بعض مهارات تصميم المواقف التعليمية . 


\section{مراجع البحث}

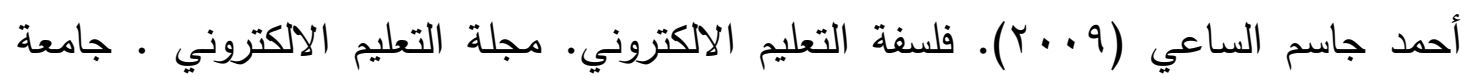

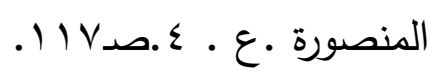

أحمد محمود عامر (Y. V V) ، عناصر التعلم الرقمية digital learning objects موقع تعلم جديد.

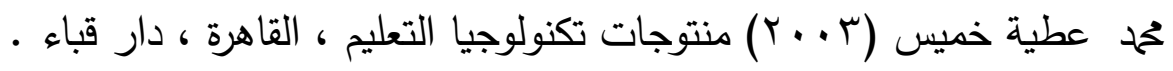

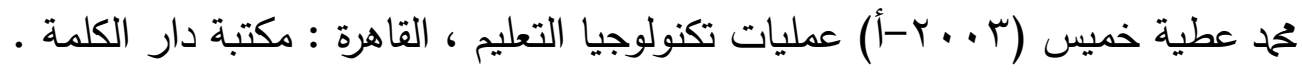
محمد عطية خميس (q. . + ) تكنولوجيا التعليم والتعلم طץ ـ القاهرة ، دار السحاب للطباعة

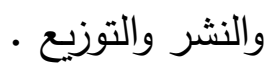

محمح عطية خميس (10 • ب). مصادر التعلم الإلكتروني. القاهرة : دار السحاب للطباع والنشر والتوزيع •

مي كمال موسي دياب(7 ( • ץ). أثر استخدام استراتيجية الرحلات المعرفية عبر الويب في تتمية مهارات الفهم التاريخي لدي طلاب المرحلة الثانوية ، مجلة الجمعية التربوية للدراسات

$$
\text { الاجتماعية ، عدد (VT)،صدع •rT. }
$$

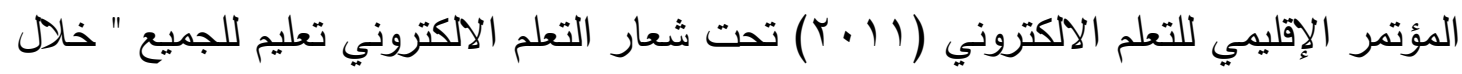

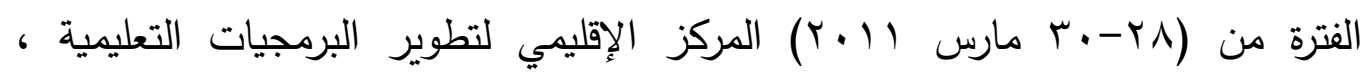
الكويت.

المؤتمر الدولي الثاني للتعلم الالكتروني في الوطن العربي (ع ا.ب) التعلم الإلكتروني التشاركي

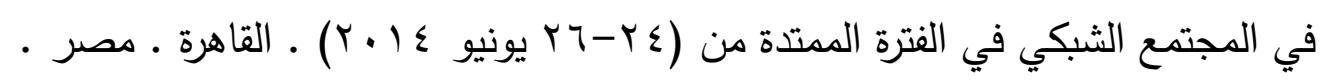

المؤتمر العلمي الرابع عشر للجمعية الهصرية لتكنولوجيا التعليم بالتعاون مع كلية التربية جامعة الأزهر (؟) (ب) تكنولوجيا التعليم والتدريب الآكتروني عن بعد وطموحات التحديث في الوطن العربي ، كلية البنات ، جامعة عين شمس ل 
مؤتمر تكنولوجيا المعلومات والاتصالات وتطوير الأداء في المؤسسات التعليمية ( با.ب؟) في

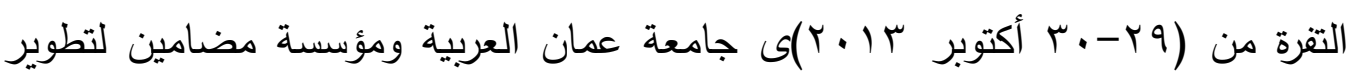

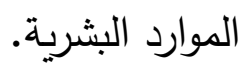
نانيس نادر ذكي حسين (Y V V • أثر استخدام استراتيجيتين للتعلم الإلكتروني التشاركي في بيئة تطبيقات جوجل علي تتمية مهارات تصميم شبكات الكمبيوتر لدي طلاب تكنولوجيا التعليم، رسالة دكتوراه ، كلية التربية النوعية ، جامعة الزقازيق •

نبيل جاد عزمي ( ( . ب) التصميم التعليمي للوسائط المتعددة ، المنيا : دار الهدي للنشر

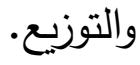

نبيل جاد عزمي (10 (Y) بيئات التعلم التفاعلية طץ، القاهرة. : يسطرون للطباعة والنشر .

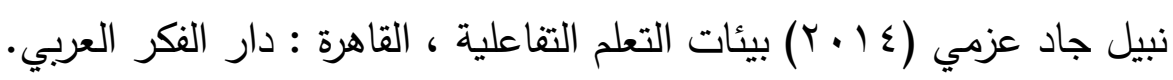

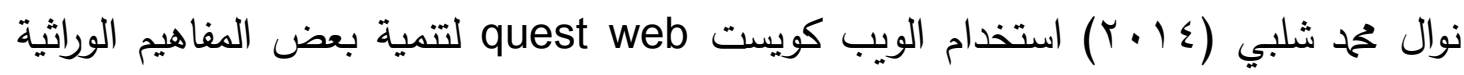

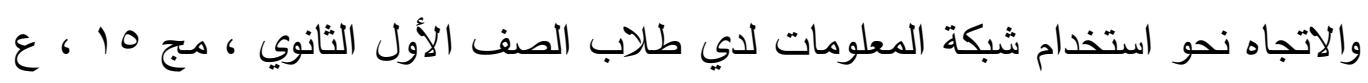

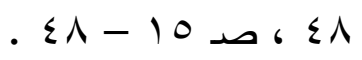

عبد العزيز طلبه عبد الحميد (· • ( + مهام الويب عبر الويب (إحدي استراتيجيات التعلم عبر

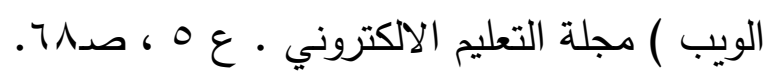

عبد العزيز طلبة عبد الحميد ( (1) أثر الاختلاف في تصميم بيئة التعلم القائم علي الويب باستخدام مستوع وحدات التعلم الرقمية في مقرر تكنولوجيا التعليم علي التحصيل وإنتاج برمجيات الوسائط المتعددة لدي طلاب كلية التربية ، دراسات في المناهج وطرق التدريس الجمعية المصرية للمناهج وطرق التدريس ، كلية التربية جامعة عين شمس ع VIT I ،

$$
\text { . NV }
$$

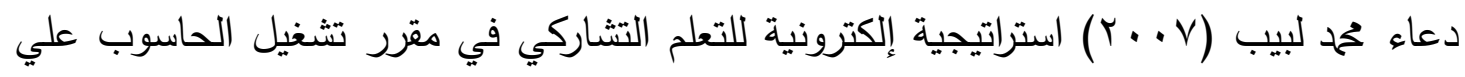
التحصيل المعرفي والمهاري والاتجاهات نحوها لطلاب الدبلوم العام في التربية شعبة كمبيوتر تعليمي ، رسالة دكتوراه ، معهد الدراسات والبحوث التربوية ، جامعة القاهرة. 
عبد العزيز طلبة عبد الحميد (9 . . (Y) فعالية استخدام استراتيجية تقصي الويب علي فعالية استخدام الرحلات تحديات التحديث التعليمية التكنولوجي ، مجلة الجمعية المصرية

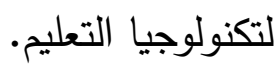

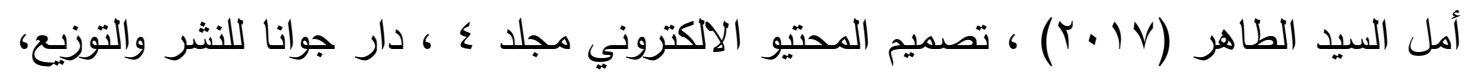
القاهرة،صدr +r.

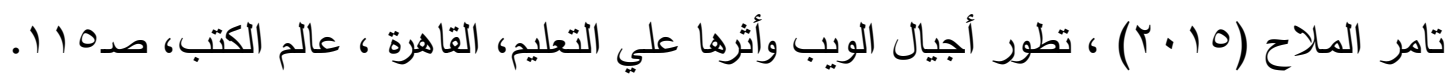
حسين محم أحمد عبد الباسط (1) (1) ، وحدات التعلم الرقمية تكنولوجيا جديدة في التعليم ، القاهرة : عالم الكتب .

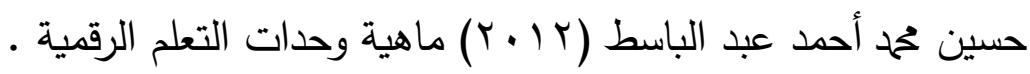
حمدان محمد إسماعيل ( T ب r) تصميم بيئة مقترحة للتعلم التشاركي قائمة علي توظيف الشبكات الاجتماعية كفضاء تعليمي اجتماعي لتتمية مهارات التواصل الاكتروني الشبكي والاتجاه

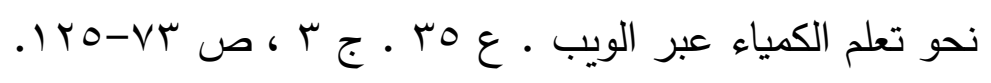

وليد يوسف محمد (10)، ب. اثر استرتيجيتين للتعلم التعاوني في تتفيذ مهام الويب علي تتمية مهارات طلاب كلية التربية منخفضي ومرتفعي الدافعية لإنجاز في تطبيقات جوجل التشاركية واستخدامها ومهاراتهم في التعليم المنظم ذاتيا دراسات عربية في التربية وعلم

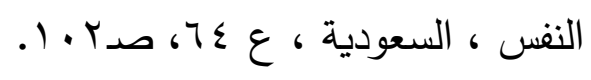




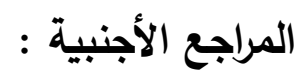

Aiison, S. (2010). Evolution of the World Wide Web: from Web 1.0 to Web 4.0. International Journal of Web \& Semantic Technology (UWesT). 3(1).

Amberg , A. Reinhardt, M., Haushahn, M. \& Hofmann, P. (2008).

Designing an Integrated Web-based persona) learning Environment Based on the cruciai success Factors of social Networks. Retrieved April 15, 20 i 5, Retrieved from:

Berkeley, 2009. Retrieved from: http://www.eecs.berkeley.edu/Pubs TechRpts/2009/EECS-2009-28.html

Drexler, W. (2010). The Networked Student Model for Construction of Personal Learning Environments: Balancing Teacher Control and Student

Autonomy. Australasian Journal of Educational Technology, 26(3). pp.

369-385

Elumalai.R. \& Ramachandran Veilumuthu. (2011). A Cloud Model for Educational e-Content Sharing, Retrieved from:

Lubensky, R. (2006). The present and future of personal leaming environments (PLE). Retrieved from: http://members.optusnet.com.au/rubensky/2006/12/presentandfutureof-personal-learning.html.-

McElvaney, J. \&Berge. (2009). Weaving a personal Web: Using online technologies to create customized, connected, and dynamic learning environment. Canadian Journal of Learning and Technology. 35 (2) spring.

Michael Armbrust, et al. (2009). Above the Clouds: A Berkeley View of Cloud Computing. Tech. rep. EECS Department, University of California,

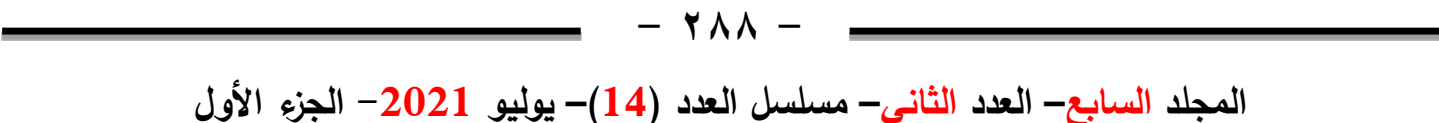


Rajkumar Buyya, et al. (2009). Cloud computing and emerging IT platforms:"

Vision, hype, and reality for delivering computing as the 5th utility". In: Future Gener. Comput. Syst. 25(6), pp. 599-616.

Staten \& James. (2008). Is Cloud Computing Ready For The Enterprise?

Cambridge: Forrester Research. 